\title{
3D printed carboxymethyl cellulose scaffolds for autologous growth factors delivery in wound healing
}

\author{
Luis Diaz-Gomez ${ }^{\text {a, }, 1}$, Iago Gonzalez-Prada ${ }^{\text {a, } 1}$, Rosendo Millan ${ }^{\mathrm{b}}$, Andres Da Silva-Candal ${ }^{\text {c,d }}$, \\ Ana Bugallo-Casal ${ }^{c}$, Francisco Campos ${ }^{c}$, Angel Concheiro ${ }^{a}$, Carmen Alvarez-Lorenzo ${ }^{a, *}$ \\ ${ }^{a}$ Departamento de Farmacología, Farmacia y Tecnología Farmacéutica, I+D Farma (GI-1645), Facultad de Farmacia and Health Research Institute of Santiago de \\ Compostela (IDIS), Universidade de Santiago de Compostela, 15782 Santiago de Compostela, Spain \\ ${ }^{\mathrm{b}}$ Centro de Biomedicina Experimental da USC (CEBEGA), Universidade de Santiago de Compostela, 15706 Santiago de Compostela, Spain \\ ${ }^{\mathrm{c}}$ Clinical Neurosciences Research Laboratory, Health Research Institute of Santiago de Compostela (IDIS), Clinical University Hospital, Universidade de Santiago de \\ Compostela, Santiago de Compostela, Spain \\ ${ }^{\mathrm{d}}$ Neurovascular Diseases Laboratory, Neurology Service, University Hospital Complex of A Coruña, Biomedical Research Institute (INIBIC), 15706 A Coruña, Spain
}

\section{A R T I C L E I N F O}

\section{Keywords:}

Carboxymethyl cellulose

3D printing

Rheological properties

microCT

Platelet rich plasma

Wound healing

Cell mobility

Angiogenesis

\begin{abstract}
A B S T R A C T
This work aims to use carboxymethyl cellulose (CMC) as main structural and functional component of 3D printed scaffolds for healing of diabetic wounds. Differently from previous inks involving small contents in CMC, herein sterile (steam-heated) concentrated CMC solely dispersions $(10-20 \% \mathrm{w} / \mathrm{v})$ were screened regarding printability and fidelity properties. CMC (15\%w/v)-citric acid inks showed excellent self-healing rheological properties and stability during storage. CMC scaffolds loaded with platelet rich plasma (PRP) sustained the release of relevant growth factors. CMC scaffolds both with and without PRP promoted angiogenesis in ovo, stem cell migration in vitro, and wound healing in a diabetic model in vivo. Transparent CMC scaffolds allowed direct monitoring of bilateral full-thickness wounds created in rat dorsum. CMC scaffolds facilitated re-epithelialization, granulation, and angiogenesis in full-thickness skin defects, and the performance was improved when combined with PRP. Overall, CMC is pointed out as outstanding component of active dressings for diabetic wounds.
\end{abstract}

\section{Introduction}

Cellulose ethers are widely used for biomedical and food applications because of their natural source-availability, biocompatibility and biodegradability (Arca et al., 2018), fulfilling the principles of green chemistry and circular economy (Chen et al., 2020). Cellulose ethers can be found in an ample variety of solid and semisolid drug dosage forms owing to their thickening and interface stabilizing roles. Particularly, carboxymethyl cellulose (CMC) leads a large-scale market, compared to other cellulose derivatives, due to the simpler and more affordable synthesis routes and raw materials and also stimuli-responsive behavior (Alvarez-Lorenzo, Blanco-Fernandez, Puga, \& Concheiro, 2013; Zennifer, Senthilvelan, Sethuraman, \& Sundaramurthi, 2021).

With the advent of 3D printing, the scope of potential applications of polysaccharides is widening. Cellulose ethers have already been demonstrated as an alternative to synthetic polymers in hot melt extrusion approaches because of their temperature-tunable softening in contrast to the melting typical of thermoplastics (Melocchi et al., 2016). Low processability temperatures are compatible with labile drugs and the obtaining of modified-release printlets (Borujeni, Mirdamadian, Varshosaz, \& Taheri, 2020; Goyanes et al., 2019; Vo, Zhang, Nyavanandi, Bandari, \& Repka, 2020). Moreover, water solubility enables the use of cellulose ethers as sacrificial material for the construction of plastic architectures with delicate external and internal patterns (Polamaplly et al., 2019). Semisolid extrusion 3D printing has also found a great ally in cellulose ethers due to the outstanding viscoelastic and selfhealing properties of their aqueous dispersions (Dai et al., 2019). In this regard, most applications have focused on the development of personalized medicines with patient-tailored drug doses and delivery patterns (Conceição et al., 2019).

In the regenerative medicine field, 3D printing allows for preparing scaffolds endorsed with adequate porous structures and patient-specific dimensions to better replicate the anatomical shape of the tissue to be repaired (Wang et al., 2019). Cellulose ethers, particularly CMC, have

\footnotetext{
* Corresponding authors.

E-mail addresses: luis.diaz.gomez@usc.es (L. Diaz-Gomez), carmen.alvarez.lorenzo@usc.es (C. Alvarez-Lorenzo).

1 Equally contributed to the work.
} 
also recently been reported as useful structural components of bioinks for wound healing due to their matrix-forming capability, cell compatibility and cross-linking feasibility (Mallakpour, Tukhani, \& Hussain, 2021). However, CMC-based inks are claimed to provide insufficient mechanical stability to the printed structures and, thus, incorporation of a variety of additives is assumed as mandatory (Zennifer et al., 2021). Nevertheless, this drawback could be related to the relatively low CMC concentrations tested so far. Additionally, since the use of CMC as the sole structural component of scaffolds has not been explored yet, conclusions about the true functionalities that CMC may have on its own are limited. Although there is still a paucity of information on the specific cell pathways that CMC may trigger, it has been suggested that CMC can be recognized by cells through receptors for glucose (GluT-1 receptor) because the glucopyranose units resemble the cyclized form of glucose, which is the predominant form in physiological environments; it does not interfere with the CD44 hyaluronic acid receptor (even though CMC has anionic groups); and it does not alter cell proliferation (Garrett et al., 2007). Remarkably, CMC has been shown to induce by itself the chemotactic migration of a variety of cells and to facilitate cell migration in response to soluble factors (Singh, Kothapalli, Varma, Nicoll, \& Vazquez, 2014). CMC may also protect scaffolds from adsorption of serum albumin (Paribok, Solomyanskii, \& Zhavnerko, 2016), which is a recognized inhibitor of mesenchymal stem cells (MSC) chemotaxis. These findings suggest that CMC may favor scaffold colonization by cells and subsequent tissue growth, behaving as an active player in tissue regeneration in addition to its process-enabling and structural role for 3D printing.

The high swelling and transparency typical of cellulose ethers hydrogels (Mallakpour et al., 2021) may also represent outstanding advantages in terms of optimum moist environment and nutrients exchange (Basu, Narendrakumar, Arunachalam, Devi, \& Manjubala, 2018; Capanema et al., 2018; Habib, Sathish, Mallik, \& Khoda, 2018) as well as visual assessment. Transparent wound dressings allow direct monitoring of the tissue underneath avoiding the risk of altering the healing process due to dressing removal (Oliverius et al., 2021).

The aim of this work was to design 3D printed CMC-based scaffolds that can help to address the unmet clinical challenge of wound chronification in diabetic patients. Diabetic ulcers present reduced expression of key growth factors and blood supply and an enhanced proteolytic activity, which inhibit new tissue formation (Pino-Sedeño et al., 2019). This work relies on the hypothesis of that inks made of CMC at sufficiently high concentration may provide 3D scaffolds for wound healing with the multi-fold functionalities of adequate exudate uptake, increased cell mobility for faster healing, and transparency for tissue monitoring. Moreover, the well-known compatibility of cellulose ethers with proteins may make CMC scaffolds as outstanding platforms for controlled release of growth factors while preserving them from degradation. Platelet rich plasma (PRP) is a safe and cost-effective source of autologous growth factors able to stimulate wound regeneration by promoting neovascularization and tissue remodeling, shortening the healing of diabetic ulcers (Babaei et al., 2017; Qian et al., 2020; Suresh, Suryanarayan, Sarvajnamurthy, \& Puvvadi, 2014). Nevertheless, direct administration of PRP and recombinant growth factors is hindered by their short half-life and the intense degradative environment in the wound site, and thus platforms that can regulate the stability and time of permanence of growth factors in the wound site are demanded (Long, Johnson, Jeffries, Hara, \& Wang, 2017; Lu et al., 2016; Yang et al., 2011; Yassin, Dawoud, Wasfi, Maher, \& Fayez, 2019). To carry out the work, first CMC dispersions with adequate self-healing properties and that can be steam-heat sterilized and stored were screened in terms of rheological properties and printability. Citric acid was chosen as a green, safe cross-linker that could modulate the integrity of the scaffold in the wound (Coma, Sebti, Pardon, Pichavant, \& Deschamps, 2003; Ghorpade, Yadav, \& Dias, 2017). Porous scaffolds were 3D printed, loaded with PRP, and characterized in terms of mechanical properties, controlled release of growth factors, in ovo angiogenesis, and in vitro promotion of cell migration and proliferation. Finally, the wound healing properties of CMC scaffolds with and without PRP were tested in vivo using a type 1 diabetic rat wound defect model, and angiogenesis, cell proliferation and new tissue formation were evaluated.

\section{Materials and methods}

\subsection{Materials}

Sodium carboxymethylcellulose (CMC, $395 \mathrm{kDa}$, degree of substitution (DS) 0.9 , viscosity $2 \% \mathrm{NF} 2960 \mathrm{cPs}, 8.8 \% \mathrm{Na}$ ) was from Ashland (Blanose ${ }^{\circledR}$ 9M31F PH; Wilmington, DE, USA). Citric acid 1-hydrate (CA) was from Panreac (Barcelona, Spain). DMEM (Dulbecco's Modified Eagle Medium), MEM $\alpha$ (Minimum Essential Medium $\alpha$ ), fetal bovine serum (FBS), penicillin/streptomycin $100 \times$ solution, TryplE $\AA$, and phosphate buffer saline (PBS) were from ThermoFisher Sci (Waltham, MA, USA). Streptozotocin was from Sigma-Aldrich (St. Louis, MO, USA). Cell Counting Kit-8 (CCK-8) was from Dojindo (Kumamoto, Japan). Ultrapure water (resistivity $>18.2 \mathrm{M} \Omega . \mathrm{cm}$ at $25^{\circ} \mathrm{C}$ ) was obtained by reverse osmosis (MilliQ ${ }^{\circledR}$, Millipore; Madrid, Spain). Adipose-derived mesenchymal stem cells (MSCs; ATCC-PCS-500-011) were from the American Type Culture Collection (Manassas, VA, USA).

\subsection{Preparation and characterization of CMC inks}

CMC (10, 15 and 20\%w/v) aqueous dispersions were prepared by mixing CMC powder with water using a mortar and then autoclaved $\left(121{ }^{\circ} \mathrm{C}, 20 \mathrm{~min}\right)$. After preliminary tests, only 15\% CMC dispersions were chosen to prepare the inks. To do that, citric acid $\left(20 \% \mathrm{w} / \mathrm{w}_{\mathrm{CMC}}\right)$ was added to the CMC dispersions and homogeneously mixed in a mortar in a clean environment (laminar flow cabinet) (Fig. 1).

Rheological properties of CMC inks (with and without citric acid) were characterized, in triplicate, using a MCR 302 rheometer (Anton Paar; Graz, Austria) fitted with a Peltier module and a plate $(15 \mathrm{~mm}$ diameter, $1 \mathrm{~mm}$ gap, $20^{\circ} \mathrm{C}$ ). $\mathrm{G}^{\prime}$ (storage modulus) and $\mathrm{G}^{\prime \prime}$ (loss modulus) were recorded applying five cycles: $0.5 \%$ shear strain at $1 \mathrm{~Hz}$ for $300 \mathrm{~s}$ (simulating rest conditions: inside the printing barrel or onto the printing platform), $100 \%$ shear strain at $1 \mathrm{~Hz}$ for $120 \mathrm{~s}$ (mimicking the pressure applied during extrusion), $0.5 \%$ shear strain at $1 \mathrm{~Hz}$ for $300 \mathrm{~s}$, $100 \%$ shear strain at $1 \mathrm{~Hz}$ for $120 \mathrm{~s}$, and $0.5 \%$ shear strain at $1 \mathrm{~Hz}$ for 300 s (Conceição et al., 2019). One batch of steam-heat sterilized CMC dispersions was stored at $22{ }^{\circ} \mathrm{C}$ protected from light, and the rheological properties were monitored along time. At pre-established time points, vials were opened and portions of CMC inks were evaluated before and after adding citric acid (as explained above). CMC ink printability was also assessed using the filament drop test and the pore shape geometry test (Gillispie et al., 2020; Paxton et al., 2017).

\section{3. $3 D$ printing of scaffolds}

Sterile CMC inks immediately after the incorporation of the citric acid were poured into $3 \mathrm{~mL}$ printing cartridges and extruded at $22{ }^{\circ} \mathrm{C}$ through a $22 \mathrm{G}$ conical needle $(0.41 \mathrm{~mm}$ inner diameter) at $2 \mathrm{~mm} / \mathrm{s}$ feeding rate and $5 \mathrm{~mm} / \mathrm{s}$ deposition speed. Scaffolds were printed as a cylinder (10 $\mathrm{mm}$ in diameter, $2 \mathrm{~mm}$ height, $1.2 \mathrm{~mm}$ on-center spacing) with a $90^{\circ}$ crosshatch pattern using a Bio V1 3D printer (Regemat3D; Granada, Spain). Immediately after printing, scaffolds were frozen at $-80{ }^{\circ} \mathrm{C}$ and freeze-dried for $24 \mathrm{~h}$ in a LyoQuest freeze dryer (Telstar; Barcelona, Spain). Freeze-dried scaffolds were then crosslinked by thermal treatment at $120^{\circ} \mathrm{C}$ for $7 \mathrm{~min}$ (Coma et al., 2003) and stored at room temperature (Fig. 1).

\subsection{Preparation of PRP-loaded scaffolds}

PRP was obtained from human buffy coat from the Galician Blood 


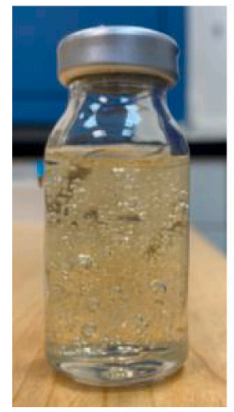

CMC dispersion

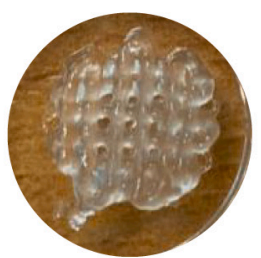

CMC-PRP scaffold

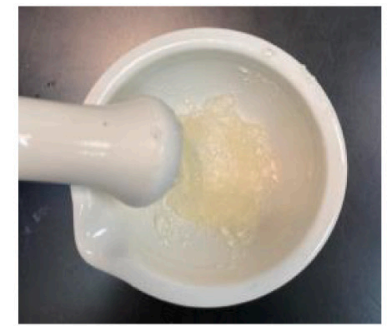

Citric acid incorporation
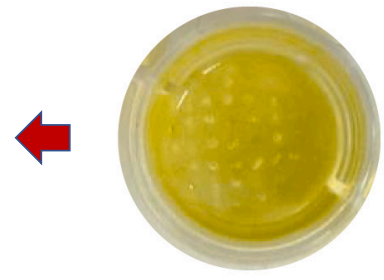

PRP incubation

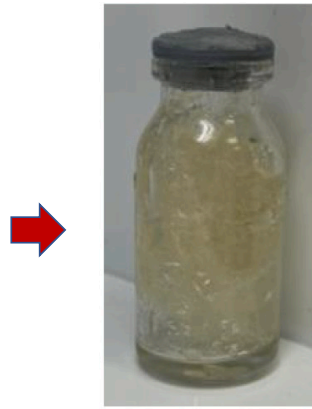

CMC-CA ink
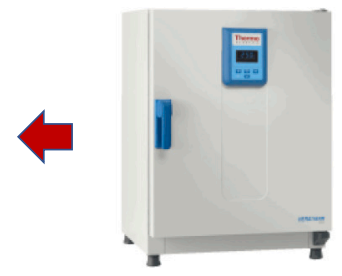

Cross-linking $\left(120^{\circ} \mathrm{C}\right)$

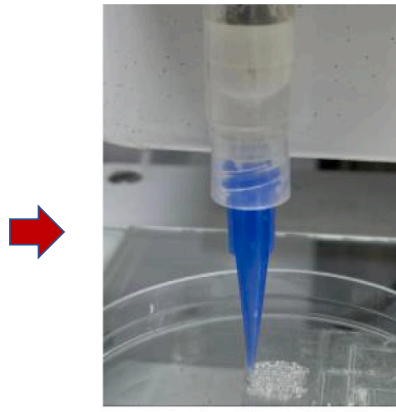

Printing

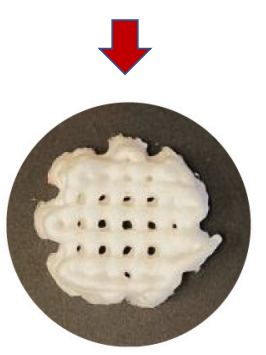

Freeze-drying

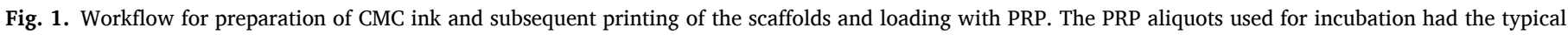
yellow color. PRP-loaded scaffolds were transparent and colorless.

and Tissue Donation Agency. Buffy coat was collected from anonymized healthy donors after obtaining written informed consent, in agreement with Spain legislation (Law 14/2007 on Biomedical Research). Aliquots $(8 \mathrm{~mL}$ ) of fresh buffy coat were transferred to $15 \mathrm{~mL}$ conical tubes and centrifuged at $1400 \mathrm{rpm}$ for $15 \mathrm{~min}$ (Eppendorf centrifuge; Hamburg, Germany). The upper phase containing the plasma rich in platelets was collected, and platelet concentration was measured using a hemocytometer (ABX Pentra XL 80; Horiba medical; Kyoto, Japan) resulting in $1.9 \cdot 10^{6}$ platelets $/ \mu \mathrm{L}$. PRP was then activated by three consecutive freeze-thaw cycles (frozen at $-80^{\circ} \mathrm{C}$ followed by incubation at $37^{\circ} \mathrm{C}$ for $1 \mathrm{~h}$ ). Activated PRP was then centrifuged at $10,000 \mathrm{~g}$ for $10 \mathrm{~min}$ at $4{ }^{\circ} \mathrm{C}$. Subsequently, the supernatant showing a clear yellowish aspect was collected and frozen at $-80{ }^{\circ} \mathrm{C}$ until use. Freeze-dried CMC scaffolds were placed individually in 24-well plates and incubated with $1.5 \mathrm{~mL}$ of activated PRP for $2 \mathrm{~h}$ at $22{ }^{\circ} \mathrm{C}$. The resultant CMC-PRP scaffolds were used immediately after preparation.

\subsection{Scaffold characterization}

\subsubsection{Swelling}

Freeze-dried CMC scaffolds (without PRP; $n=5$ ) were individually placed in 24-well plates containing $1.5 \mathrm{~mL}$ of water, $\mathrm{NaCl} 0.9 \% \mathrm{w} / \mathrm{v}$, or activated PRP and incubated at $37{ }^{\circ} \mathrm{C}$ for $24 \mathrm{~h}$. At pre-established timepoints, scaffolds were taken from the swelling media, the excess of fluid was removed, and the weight and dimensions of each scaffold were recorded using a precision scale and a caliper, respectively. The fluid uptake of the scaffolds was calculated as follows:

Fluid uptake $(\%)=100 \times\left[\frac{W_{w}-W_{d}}{W_{d}}\right]$

where $\mathrm{W}_{\mathrm{w}}$ and $\mathrm{W}_{\mathrm{d}}$ represent the weights of wet and dry scaffolds, respectively.

In parallel, the mass loss of the scaffolds during incubation in $\mathrm{NaCl}$ $0.9 \% \mathrm{w} / \mathrm{v}$ was calculated by taking scaffolds from the medium at each timepoint, which were rinsed with water, freeze-dried and weighed. The mass loss was calculated from the initial mass for each scaffold.

\subsubsection{Structure analysis}

Freeze-dried scaffolds (CMC scaffolds before and after crosslinking, and CMC-PRP scaffolds; $n=5$ ) were sputter-coated using gold-palladium and analyzed using an EVO LS 15 scanning electron microscope (Zeiss; Oberkochen, Germany). The microporous structure was also evaluated using a SkyScan 1272 X-ray microCT (Bruker; Kontich, Belgium) with a resolution of $3 \mu \mathrm{m} /$ pixel and no filter. The obtained projections were reconstructed using Nrecon software and the analysis of the structure was carried out with CTAn software.

\subsubsection{FTIR-ATR}

Attenuated total reflectance Fourier-transform infrared (FTIR-ATR) spectra of freeze-dried CMC and CMC-PRP scaffolds and raw materials (CMC, citric acid, and freeze-dried PRP) were recorded using a Varian 670-IR (Varian Inc.; Palo Alto, CA) within the $400-4000 \mathrm{~cm}^{-1}$ range at a resolution of $2 \mathrm{~cm}^{-1}$.

\subsubsection{Mechanical properties}

CMC scaffolds ( $n=5 ; 10 \mathrm{~mm}$ diameter, $5 \mathrm{~mm}$ height) swollen in $\mathrm{NaCl}$ $0.9 \%$ or PRP for $2 \mathrm{~h}$ were transferred to Petri dishes and their compressive properties were determined applying an unconfined compression test at crosshead speed of $1 \mathrm{~mm} / \mathrm{s}$ and an activation force of $0.1 \mathrm{~g}$ using a TA.XTplus Texture Analyzer (Stable Micro Systems; Surrey, UK) fitted with a 5-kg load cell. The force-deformation curves were recorded for two consecutive compression/decompression cycles of each scaffold, and hardness, cohesiveness, and adhesiveness were calculated (Hurler, Engesland, Poorahmary Kermany, \& Škalko-Basnet, 2012).

\subsection{Growth factors release}

Immediately after PRP loading, CMC-PRP scaffolds were placed individually in LoBind microcentrifuge tubes (Eppendorf; Hamburg, Germany) and $\mathrm{NaCl} 0.9 \% \mathrm{w} / \mathrm{v}$ aqueous solution $(1 \mathrm{~mL})$ was added to each tube. The tubes were maintained at $37^{\circ} \mathrm{C}$ and, at pre-established timepoints, aliquots $(0.5 \mathrm{~mL})$ of release media were collected and replaced with the same volume of fresh $\mathrm{NaCl} 0.9 \% \mathrm{w} / \mathrm{v}$ solution. The 
aliquots were stored at $-80{ }^{\circ} \mathrm{C}$ until analysis. Total protein release was evaluated using Pierce BCA Protein Assay Kit (ThermoFisher Sci.; Waltham, MA, USA). Transforming growth factor- $\beta 1$ (TGF- $\beta 1$ ) and vascular endothelial growth factor (VEGF) were quantified using enzyme-linked immune sorbent assay (ELISA) kits (Invitrogen, Carlsbad, CA, USA). Results were expressed as the cumulative release obtained after normalizing the amount of growth factors at each time-point to the total amount present in the scaffold $(n=5)$.

\subsection{In ovo evaluation}

A chorioallantoic membrane (CAM) assay was implemented to evaluate cell infiltration and neovascularization in the scaffolds (Merckx et al., 2020). Fertilized hen eggs (50-60 g, Coren; Orense, Spain) were incubated as described before (Diaz-Gomez et al., 2014). On day 3, a window was opened on the pointed end of the eggs to facilitate the dissociation of the CAM from the shell membrane, and the eggs were returned to incubation. On day 8 , scaffolds $(n=5)$ were placed individually in direct contact with the CAM and incubated again. As controls, $200 \mu \mathrm{L}$ of activated PRP were placed on the surface of the CAM. Finally, on day 12 of incubation, the window was widened, and the CAM was fixed in $10 \%$ formalin for $3 \mathrm{~h}$. New vessel formation was assessed for each material by observing and counting the number of microvessels converging towards the scaffold using a stereomicroscope.

\subsection{Cell proliferation and migration}

MSCs were seeded in 24-well plates with CMC or CMC-PRP scaffolds individually placed $(n=5)$ in inserts and cell proliferation was evaluated using a CCK- 8 assay at 24, 48 and 96 h. A scratch assay was also carried out to evaluate the ability of the substances being released from the scaffolds (after $24 \mathrm{~h}$ incubation in complete culture medium at $37^{\circ} \mathrm{C}$ ) to promote MSCs migration. Details are provided in S1 (Supplementary material). No changes in color of culture medium due to unreacted citric acid were observed.

\subsection{In vivo wound healing assay}

In vivo procedures were approved by the University of Santiago de Compostela Bioethics Committee for Animal Studies (protocol No. $15007 / 16 / 001)$ and conducted in accordance with the European regulation on care and use of animals in experimental procedures and the ARRIVE guidelines. Healthy male Sprague Dawley rats (18 animals, 200-250 g) were acclimatized for 7 days in cages at $23 \pm 2{ }^{\circ} \mathrm{C}$ under $12 \mathrm{~h}$ light/dark cycle and ad libitum feeding. On day 4, diabetes was induced using intraperitoneal injections of streptozotocin $(60 \mathrm{mg} / \mathrm{kg})$. The animals were housed for 6 weeks to ensure a delayed healing phenotype (Ansell, Marsh, Walker, Hardman, \& Holden, 2018; Elliot, Wikramanayake, Jozic, \& Tomic-Canic, 2018), and glucose levels were monitored weekly (Glucocard SM; Menarini Firenze, Italy). All 18 rats had glucose levels higher than $250 \mathrm{mg} / \mathrm{dL}$, polyuria, polydipsia and polyphagia one week after diabetes induction and were included for the study. At week 6 , animals were anesthetized using $2.5 \%$ isoflurane. The dorsal skin was shaved using a trimmer. Then, four symmetrical, full-thickness wounds of $8 \mathrm{~mm}$ in diameter were created on the back of each animal using sterile disposable biopsy punches (Kai Medical, Seki City, Japan). The animals were randomly divided into 3 groups (time points 3, 7, and 14 days) and the wounds of each rat were randomly divided into 3 treatment groups ( $n=7$ ): 1-untreated controls; 2-CMC scaffolds (swollen in $\mathrm{NaCl} 0.9 \%$ for $2 \mathrm{~h}$ ); 3 -CMC-PRP scaffolds ( $\mathrm{h}$ loading in PRP). Transparent films (Tegaderm ${ }^{\mathrm{TM}} 3 \mathrm{M}$; Maplewood, MN, USA) were used to cover the wound sites during the first $24 \mathrm{~h}$ after scaffold implantation to prevent the animals from removing the scaffolds (Ramli \& Wong, 2011). After surgery, animals returned to individual cages until the end of the study.

The wound area was determined from digital photographs obtained daily during the first week and every other day thereafter and processed using ImageJ (NIH; Bethesda, MD, USA). The wound closure rate was calculated as follows:

Re-epithelialization $(\%)=100 \times\left[\frac{\text { Wound area at } t_{0}-\text { Wound area at } t_{t}}{\text { Wound area at } t_{0}}\right]$

Animals were euthanized at 3, 7 or 14 days after surgery by carbon dioxide inhalation. Wound site biopsies were collected using $8 \mathrm{~mm}$ biopsy punches and fixed in 4\% paraformaldehyde for histopathological (hematoxylin and eosin (H\&E) staining) and immunohistochemical (CD31 and PCNA) analysis (S2 and S3 in Supplementary material). The skin biopsies were then embedded in OCT resin (Tissue-Tek, Sakura Finetek; Tokyo, Japan), sliced in sections of $15 \mu \mathrm{m}$ using a cryostat and fixed on glass slides.

\subsection{Statistical analysis}

One-way analysis of variance (ANOVA) and Tukey's multiple comparison posttests were performed using GraphPad Prism (GraphPad software; La Jolla, CA). Differences were considered significant for $p<$ 0.05 .

\section{Results and discussion}

\subsection{Preparation of CMC-PRP scaffolds}

In this work, CMC and autologous PRP were combined in 3D printed porous scaffolds endorsed with a well-defined, personalized structure for the regeneration of chronic wounds. CMC was selected due to its remarkable printability and bioactivity, including cell migration properties (Garrett et al., 2007). Wound dressings prepared with medium and high molecular weight CMCs have been shown to induce faster healing rates than those prepared with low molecular weight CMC due to better moisture and water loss control (Kanikireddy, Varaprasad, Jayaramudu, Karthikeyan, \& Sadiku, 2020; Ramli \& Wong, 2011). Furthermore, a substitution degree in the $0.8-1$ range is desired to achieve adequate mechanical and swelling properties for wound healing applications (Capanema et al., 2018). Thus, a CMC with medium molecular weight (395 kDa) and a substitution degree of 0.9 was chosen.

Preliminary studies were carried out with inks containing CMC at 10, 15 and $20 \% \mathrm{w} / \mathrm{v}$ to assess extrudability, shape fidelity and reproducibility (Gillispie et al., 2020). CMC 10\%w/v dispersions led to strands with low mechanical properties and poor shape fidelity, resulting in the collapse of the scaffolds due to the sagging of the fibers under the weight of the scaffold. CMC 15\%w/v dispersions allowed for the fabrication of scaffolds with well-defined structure, high printing fidelity and unrestricted height in the evaluated range (Table S1 in Supplementary material). The filament drop test (Paxton et al., 2017) confirmed that the ink showed proper gel properties after extrusion, and a uniform, continuous, smooth filament was formed at the nozzle tip. As expected, the extruded filament led to homogeneous structures with accurate pore geometries close to perfect square shapes disregarding the pore size. Differently, CMC $20 \% \mathrm{w} / \mathrm{v}$ inks led to "over-gelled" bumpy filaments, and scaffold printing required longer time and extrusion pressure close to the limit of the printer. Therefore, CMC 15\%w/v dispersions were chosen to prepare the $3 \mathrm{D}$ printed scaffolds.

CMC dispersions were steam heated at $121^{\circ} \mathrm{C}$ before printing with the two-fold aim of (i) favoring the full hydration of the cellulose ether chains to avoid the presence of partially-hydrated colloidal particles (Savage, 1971), and (ii) obtaining a sterile preparation readily available for on-demand 3D printing. Heating at $121{ }^{\circ} \mathrm{C}$ for short time has been shown not to alter CMC molecular weight (Hiltunen, Xu, Willför, \& Backfolk, 2018). The rheological properties of the inks were evaluated to assess in more detail their behavior during printing and also to elucidate 
the effect of storage on printability (Conceição et al., 2019; Zidan et al., 2019). A cyclic sweep test mimicked the conditions applied to the inks during the printing process; namely, a rapid increase in the stress to simulate the pressure applied to the cartridge during the extrusion, followed by a release of pressure. CMC dispersions, both before and after addition of CA, showed a gel-like behavior $\left(\mathrm{G}^{\prime}>\mathrm{G}^{\prime \prime}\right.$ at $0.5 \%$ strain) (Fig. 2). Simulation of the extrusion conditions (sudden increase to $100 \%$ strain) caused an immediate decrease in both moduli values, with a more pronounced drop in $\mathrm{G}^{\prime}$. The decrease of the strain back to a resting state $(0.5 \%)$ allowed for a rapid recovery of $\mathrm{G}^{\prime}$ to values close to the initial ones. Application of successive cycles resulted in similar instantaneous recoveries of $\mathrm{G}^{\prime}$, indicating the adequate self-healing properties of the CMC dispersions for their use as inks for biofabrication purposes (Seoane-Viaño, Januskaite, Alvarez-Lorenzo, Basit, \& Goyanes, 2021). Replicates of each dispersion presented similar $\mathrm{G}^{\prime}$ and $G^{\prime \prime}$ values, which indicated the homogeneity of the CMC inks. Importantly, the rheological properties of the inks were not significantly altered during the storage, showing a minor increase in $\mathrm{G}^{\prime}$ and $\mathrm{G}^{\prime \prime}$ after 14 days storage (Fig. 2) that did not alter the printing parameters needed to extrude the materials.

CMC inks were printed as cylindrical scaffolds with diameters of 10 $\mathrm{mm}$ (for structural characterization and in vitro studies) or $8 \mathrm{~mm}$ (for in vivo studies). Since macropores of size between $50 \mu \mathrm{m}$ and $1 \mathrm{~mm}$ are preferable for tissue regeneration (Saghazadeh et al., 2018), the on-
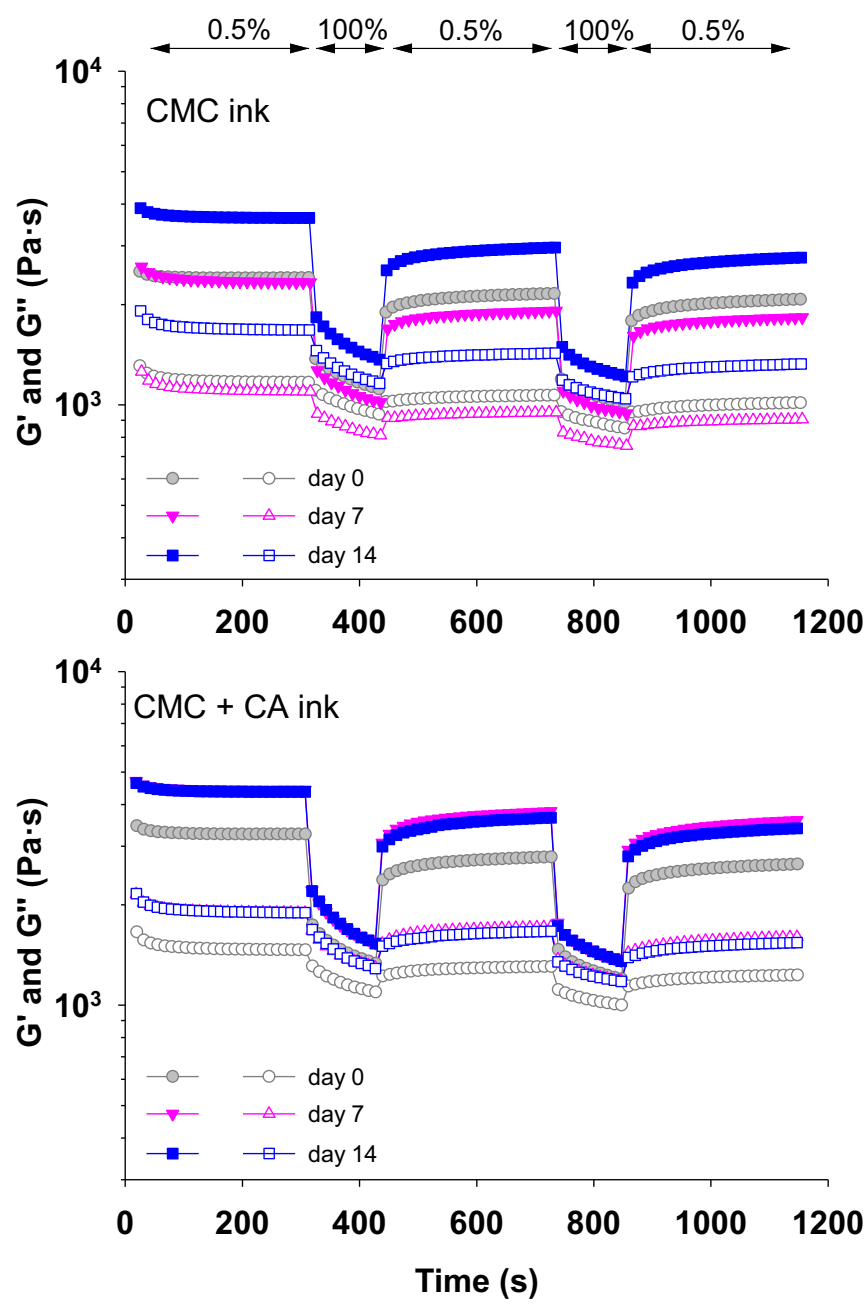

Fig. 2. Rheological properties of CMC dispersions with and without citric acid (CA) as freshly prepared and after storage (7 and 14 days at $22{ }^{\circ} \mathrm{C}$ in closed containers, protected from light) under cyclic changes in shear strain $(0.5 \%$ - 100\%). center spacing between strands was fixed at $1.2 \mathrm{~mm}$ to obtain $790 \mu \mathrm{m}$ gaps. The obtained structures presented high printing fidelity with respect to the original 3D model (Table 1 and Fig. 3). After printing, scaffolds were freeze-dried to preserve their 3D structure during water removal (as demonstrated for other polysaccharides; Long et al., 2019) and, subsequently, crosslinked to reinforce the mechanical strength. Citric acid $(20 \% \mathrm{w} / \mathrm{w}$ with respect to $\mathrm{CMC})$ in the ink allowed for the cross-linking in the bulk of the scaffold through an esterification reaction with the hydroxyl groups of CMC (Coma et al., 2003; Ghorpade et al., 2017). The freeze-drying step was expected to favor subsequent dehydration of citric acid to form reactive anhydride species. Citric acid contents above $10 \% \mathrm{w} / \mathrm{w}$ with respect to cellulose ethers have been shown to allow for $100 \%$ cross-linking at $190{ }^{\circ} \mathrm{C}$ in few minutes (Coma et al., 2003), but increasing the ratio up to $20 \% \mathrm{w} / \mathrm{w}$ efficient crosslinking of CMC could be obtained at much lower temperature in order to avoid chemical degradation of the cellulose ether (Demitri et al., 2008; Ghorpade et al., 2017). After preliminary studies, in our case a crosslinking time of $7 \mathrm{~min}$ at $120^{\circ} \mathrm{C}$ was selected to obtain scaffolds that combine swelling behavior (exudate uptake) and flexible structure able to adapt to the wound site. Shorter crosslinking time $(<5 \mathrm{~min}$ ) led to unstable structures that dissolved shortly after incubation at $37{ }^{\circ} \mathrm{C}$, while longer crosslinking time ( $>10 \mathrm{~min}$ ) significantly increased the stiffness and fragility of the scaffolds. Scaffolds endorsed with poor mechanical properties and high erosion rates might not be suitable for wound healing applications (Pettignano, Charlot, \& Fleury, 2019). Conversely, high crosslinking degrees have detrimental effects on the flexural properties of the dressings (required for a complete contact with the wound surface area) and may cause physical damage to the ongrowing tissue (Capanema et al., 2018).

The pore size and fiber width of the CMC scaffolds $\left(\mathrm{CMC}_{\text {freeze-dried }}\right)$ were monitored by SEM and microCT to determine the effect of crosslinking ( $\left.\mathrm{CMC}_{\text {crosslinked }}\right)$ and PRP loading (CMC-PRP) on the structure of the scaffolds (Table 1; Fig. 3). The crosslinking had no significant effect on pore size and fiber diameter. CMC scaffolds before and after crosslinking showed a dual pore population: (i) large pores of $c a .790 \mu \mathrm{m}$ resulting from the printing pattern; and (ii) a micropore population of $37.5 \pm 15.3 \mu \mathrm{m}$ and $41.3 \pm 26.2 \mu \mathrm{m}$ for CMC scaffolds before and after crosslinking, respectively, formed because of the freeze-drying process (Fig. S1).

The effect of PRP loading on the porous structure of CMC scaffolds was also investigated (Fig. 3). CMC-PRP scaffolds showed a significant increase (ca. 10\%) in the pore size and fiber width $(p<0.05)$, which can be attributed to the swelling of the CMC strands during the incubation period in the PRP medium. SEM analysis revealed a spongy-like network homogeneously distributed on the surface of the fibers and confirmed the maintenance of the micropore population on the printed fibers.

\subsection{Scaffolds characterization}

The FTIR-ATR analysis (Fig. S2) of $\mathrm{CMC}_{\text {freeze-dried }}$ and $\mathrm{CMC}_{\text {crosslinked }}$ scaffolds showed bands at $3318 \mathrm{~cm}^{-1}$ ascribed to the $-\mathrm{OH}$ stretching frequency, at $2922 \mathrm{~cm}^{-1}$ due to the $\mathrm{C}-\mathrm{H}$ stretching vibration, at 1590 $\mathrm{cm}^{-1}$ typical of cellulose ethers, and at 1715 and $1411 \mathrm{~cm}^{-1}$

Table 1

Structure parameters of the CMC scaffolds immediately after freeze-drying, once cross-linked, and after PRP loading $(n=5)$.

\begin{tabular}{|c|c|c|c|c|}
\hline Scaffold & $\begin{array}{l}\text { Diameter } \\
(\mathrm{mm})\end{array}$ & $\begin{array}{l}\text { Height } \\
(\mathrm{mm})\end{array}$ & $\begin{array}{l}\text { Pore size } \\
(\mu \mathrm{m})\end{array}$ & $\begin{array}{l}\text { Fiber diameter } \\
(\mu \mathrm{m})\end{array}$ \\
\hline 3D model & 10 & 2 & 790 & 420 \\
\hline $\begin{array}{l}\mathrm{CMC}_{\text {freeze- }} \\
\text { dried }\end{array}$ & $9.3 \pm 0.3$ & $2.0 \pm 0.0$ & $\begin{array}{l}796.3 \pm \\
45.7\end{array}$ & $444.1 \pm 30.2$ \\
\hline $\mathrm{CMC}_{\text {crosslinked }}$ & $9.6 \pm 0.2$ & $1.9 \pm 0.1$ & $\begin{array}{l}788.6 \pm \\
52.0\end{array}$ & $461.6 \pm 31.7$ \\
\hline CMC-PRP & $11.5 \pm 0.6$ & $2.1 \pm 0.2$ & $\begin{array}{l}877.9 \pm \\
87.4\end{array}$ & $510.4 \pm 43.9$ \\
\hline
\end{tabular}



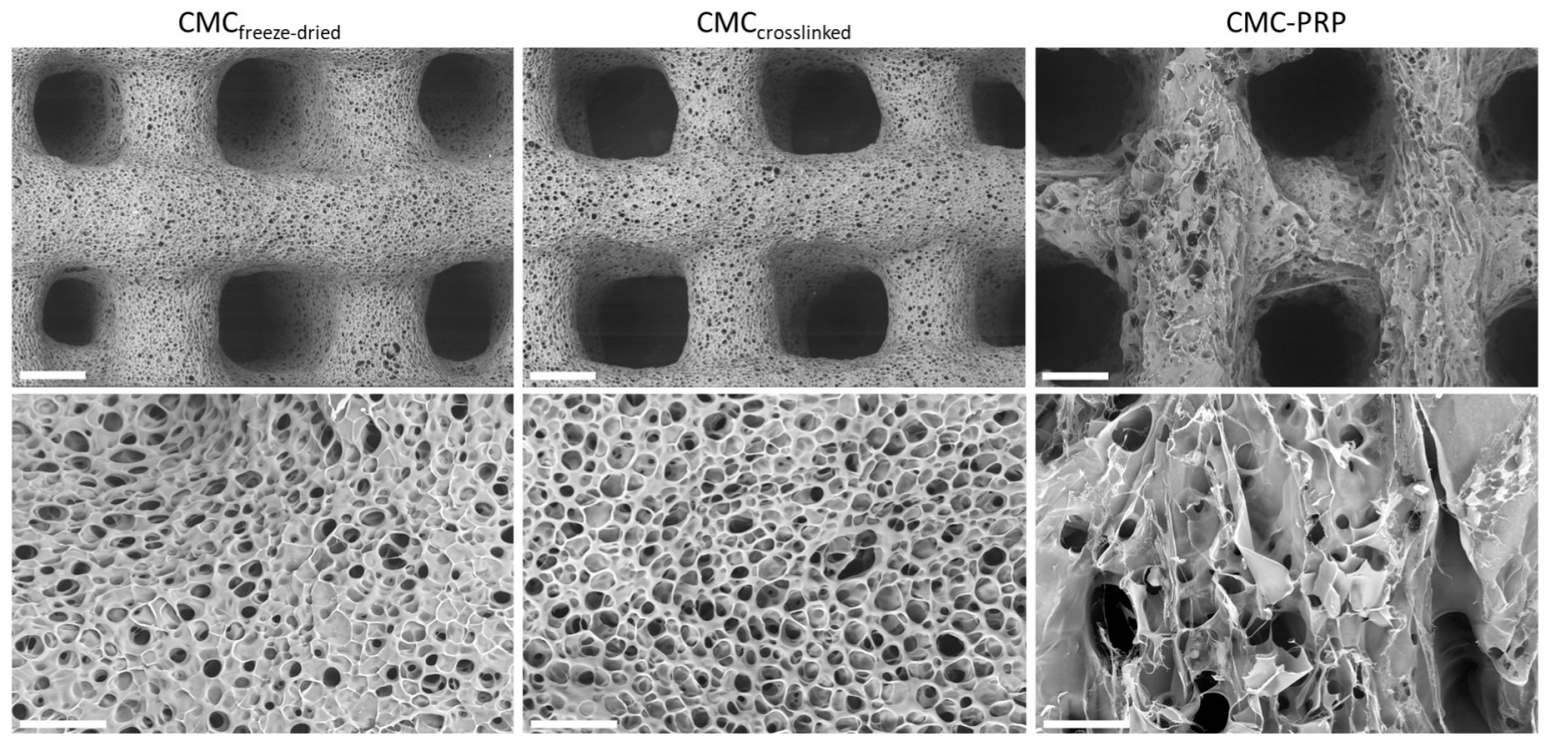

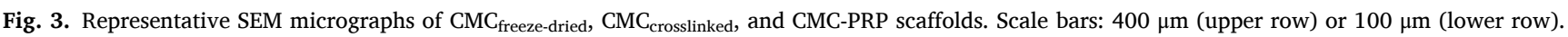

A

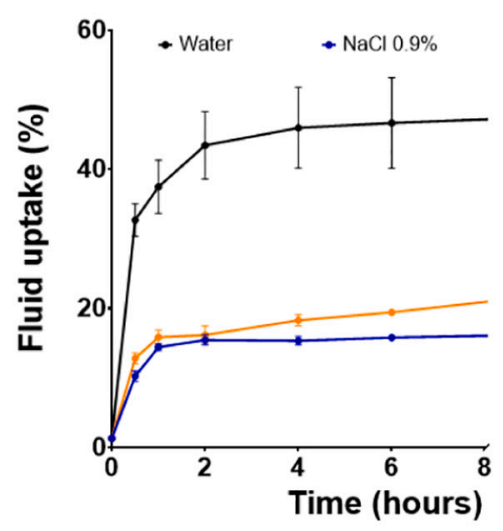

B

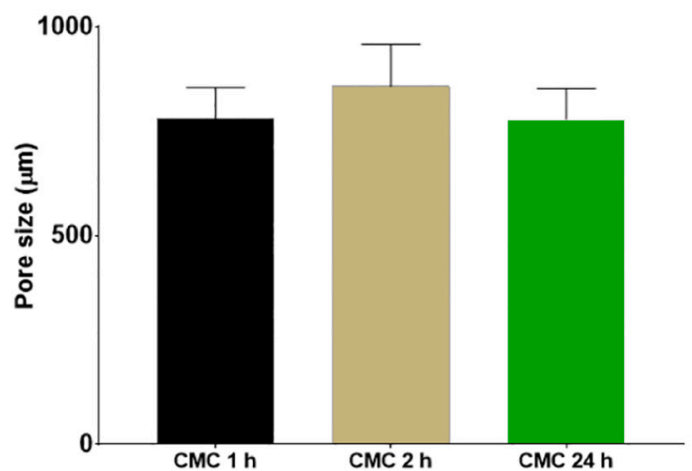

C
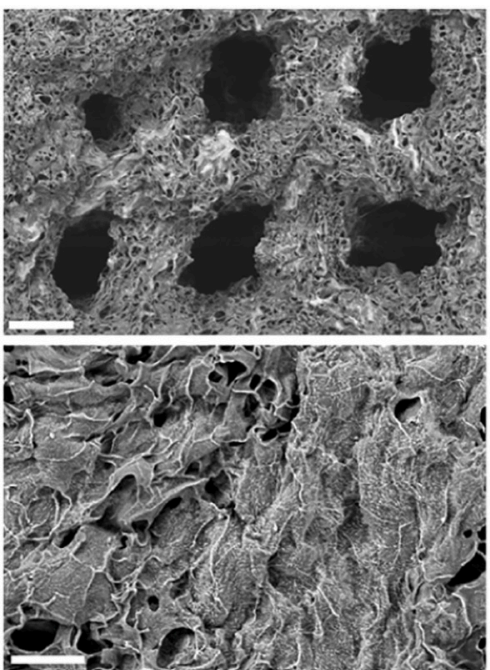

- PRP
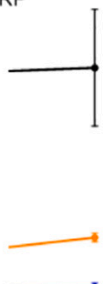

$\longdiv { 2 2 \quad 2 4 }$
$2 \mathrm{~h}$
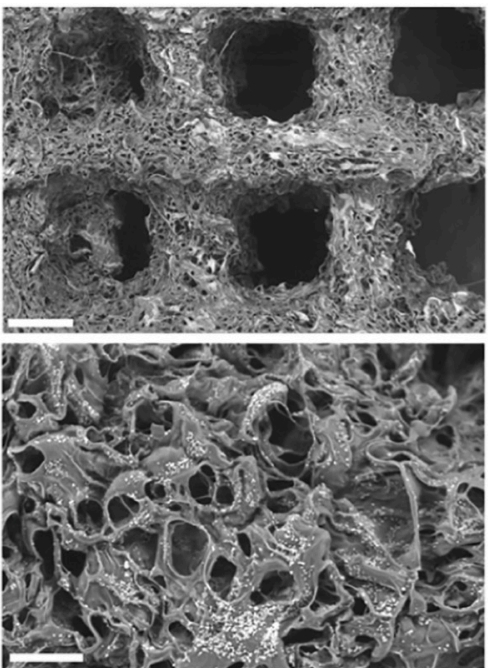

$24 \mathrm{~h}$
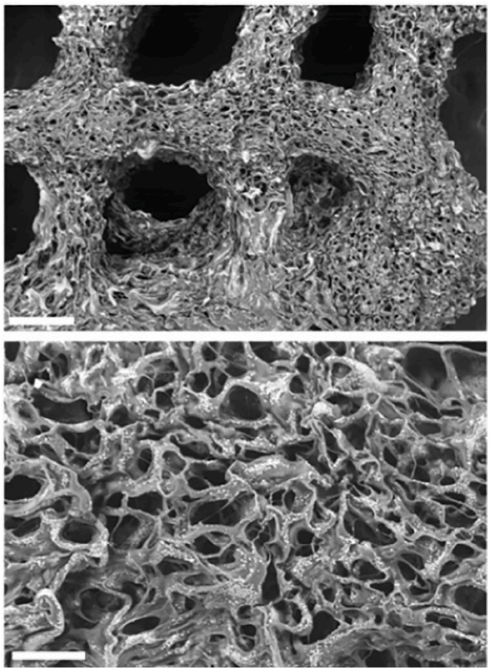

Fig. 4. (A) Fluid uptake of CMC scaffolds when incubated in water, $\mathrm{NaCl} 0.9 \%$ or PRP for $24 \mathrm{~h}$, (B) pore size (mean \pm standard deviation; $n=5$ ), and (C) SEM micrographs of freeze-dried CMC scaffolds after incubation in NaCl $0.9 \% \mathrm{w} / \mathrm{v}$ for 1,2 or $24 \mathrm{~h}$. Scale bars: $400 \mu \mathrm{m}$ (upper row) or $100 \mu \mathrm{m}$ (lower row). The size of the macropores was not significantly altered after incubation for $24 \mathrm{~h}$ in $\mathrm{NaCl} 0.9 \%(p>0.05)$. 
characteristic of carboxylic acid groups and that overlapped with those of citric acid (Demitri et al., 2008). Transient bands of anhydrides at 1758 and $1828 \mathrm{~cm}^{-1}$ were not observed because either the reaction had ended with the ester formation or the ratio of anhydride groups was too low to be detected. As previously reported, monitoring of the crosslinking by means of FTIR is more feasible in the case of non-ionic cellulose ethers that lack of carboxylic groups (Demitri et al., 2008). Nevertheless, since the reaction with citric acid should involve a decrease in primary alcohols (absorption bands at 1075-1000 $\mathrm{cm}^{-1}$ ) with respect to secondary alcohols (absorption at 1150-1075 $\mathrm{cm}^{-1}$; Langkilde \& Svantesson, 1995); the absorption peak at $1021 \mathrm{~cm}^{-1}$ was compared with that of $1091 \mathrm{~cm}^{-1}$. Pristine CMC had $\mathrm{A}_{1021} / \mathrm{A}_{1091}$ of 1.68 , while after cross-linking the ratio decreased to 1.57 , which suggested a $7 \%$ decrease in the number of primary alcohols. A $10 \%$ decrease in primary alcohols have been reported for other cellulose ethers when reacted with ethyleneglycol diglycidylether to form chemically crosslinked hydrogels (Rodríguez, Alvarez-Lorenzo, \& Concheiro, 2003; Rodriguez-Tenreiro, Alvarez-Lorenzo, Rodriguez-Perez, Concheiro, \& Torres-Labandeira, 2006). Incorporation of PRP in the CMC scaffolds was revealed by amide I and II peaks at 1660 and $1550 \mathrm{~cm}^{-1}$, respectively, and a broadening of peak in the $3300-3500 \mathrm{~cm}^{-1}$ region ascribed to $\mathrm{NH}$ groups.

Wound healing requires precise regulation of the moisture, preventing dehydration but also excessive accumulation of exudates, which may result in the degradation of key components of the extracellular matrix (Everett \& Mathioudakis, 2018). CMC scaffolds swelled fast in water, $\mathrm{NaCl} 0.9 \% \mathrm{w} / \mathrm{v}$ and PRP and the curves stabilized after $2 \mathrm{~h}$ (Fig. 4A). Water uptake values were over $40 \%$ while the swelling of scaffolds incubated in PRP and $\mathrm{NaCl} 0.9 \% \mathrm{w} / \mathrm{v}$ was close to $15 \%$ after 2 $\mathrm{h}$, which can be explained by the higher ionic strength of the latter media. The macroporous structure of the CMC scaffolds was not significantly affected by the incubation for 1,2 and $24 \mathrm{~h}$ in $\mathrm{NaCl} 0.9 \%$ medium (SEM image; Fig. 4C). The average macropore size (quantified using Image $\mathrm{J}$ software) did not experiment significant changes $(p>0.05)$ during the incubation period (Fig. 4B). Mass loss during swelling in $\mathrm{NaCl}$ $0.9 \%$ medium was also monitored and revealed $17.5 \pm 2.6 \%$ weight loss in $2 \mathrm{~h}$ and $55.2 \pm 2.4 \%$ after $24 \mathrm{~h}$. Regarding the microstructure, liquid uptake led to an apparent increase in the micropore density of the printed fibers, which can be related to the swelling of the structure and the significant mass loss during the first hours.

Regarding mechanical properties, hardness, cohesiveness and adhesiveness (Coviello et al., 2005) of the CMC and CMC-PRP scaffolds were evaluated after incubation in $\mathrm{NaCl} 0.9 \%$ or PRP for $2 \mathrm{~h}$ (Fig. S3 and Table S2). PRP loading led to a significant increase in the hardness (peak force during the first compression cycle; $124 \pm 7 \mathrm{mN} v s .94 \pm 18 \mathrm{mN}$ ) but did not change the cohesiveness (ratio of the positive force area during the second compression compared to the first cycle; $1.01 \pm 0.13 v s .1 .13$ \pm 0.07 ), a parameter related to the work needed to overcome internal bonds. Both CMC and CMC-PRP scaffolds showed similar cohesiveness values close to 1 , confirming that the porous scaffolds maintain their internal structure during consecutive compressive stresses; namely, the different layers of the 3D network were successfully entangled at the contact points and the scaffolds performed as quasi-perfectly elastic materials. Adhesiveness (i.e., the negative area during the first compression cycle) of CMC-PRP scaffolds $(13.20 \pm 3.99 \mathrm{~mJ})$ was one order of magnitude higher compared to CMC scaffolds $(1.33 \pm 1.17 \mathrm{~mJ})$, which suggests an increase in tackiness of the scaffold due to the fibrin present in the activated PRP (Hurler et al., 2012; Pavlovic, Ciric, Jovanovic, Trandafilovic, \& Stojanovic, 2021).

\subsection{Growth factors release}

Cumulative amounts of total protein released from CMC-PRP scaffolds in $\mathrm{NaCl}$ 0.9\% (BCA assay; Fig. 5A) showed a burst within the first 6 $\mathrm{h}$ of incubation, followed by a more controlled release rate. The cumulative protein released was $232 \pm 41 \mu \mathrm{g}$ per mg of scaffold after $72 \mathrm{~h}$ of incubation. At day 7, the scaffolds were completely disintegrated, thus it can be assumed that the growth factors contained in the scaffolds were $100 \%$ released. This time frame of release may fit to the requirements of wound dressings, which are optimally inspected or replaced one to two times a week in order to avoid healing disturbances (Berg, Lazaro Martinez, Serena, Dhoonmoon, \& Ousey, 2019; Kavitha, 2014). The protein release pattern recorded for CMC-PRP scaffolds was consistent with previous findings for scaffolds having large and interconnected pores (Diaz-Gomez et al., 2014; Long et al., 2019). CMC-PRP scaffolds can provide a steep delivery of growth factors to start the therapeutic effect immediately after implantation, which is especially relevant in the case of diabetic wounds characterized by impaired growth factors availability (Kavitha, 2014; Pino-Sedeño et al., 2019). Then, sustained release rate might be useful to maintain the concentration of growth factors in the wounded area for several days (Saghazadeh et al., 2018).

Regarding individual growth factors release, VEGF was rapidly delivered showing the maximum at $24 \mathrm{~h}$, with $18.6 \pm 4.8 \mathrm{pg}$ VEGF released per mg of CMC-PRP scaffold (Fig. 5B). During normal healing VEGF secretion is elevated in the first 2-3 days to stimulate angiogenesis, vasodilation, endothelial cell migration and proliferation, and collagen deposition (Bao et al., 2009). However, VEGF secretion in diabetic wounds is very limited, which contributes to chronification (Babaei et al., 2017; Bao et al., 2009). The delivery of significant concentrations of VEGF during the initial hours of treatment in diabetic wounds, as observed for CMC-PRP scaffolds, could positively impact the healing by promoting chemotaxis and angiogenesis.

Differently, TGF- $\beta 1$ was sustainedly released over 7 days (Fig. 5C). By the end of the study, the amount of TGF- $\beta 1$ released was $821.1 \pm$ 405.2 pg per mg of CMC-PRP scaffold. Compared to VEGF, TGF- $\beta 1$ is significantly involved in all the stages of wound healing promoting the formation and organization of granulation tissue; thus, sustained release at the wound site is desired in order to stimulate the regeneration

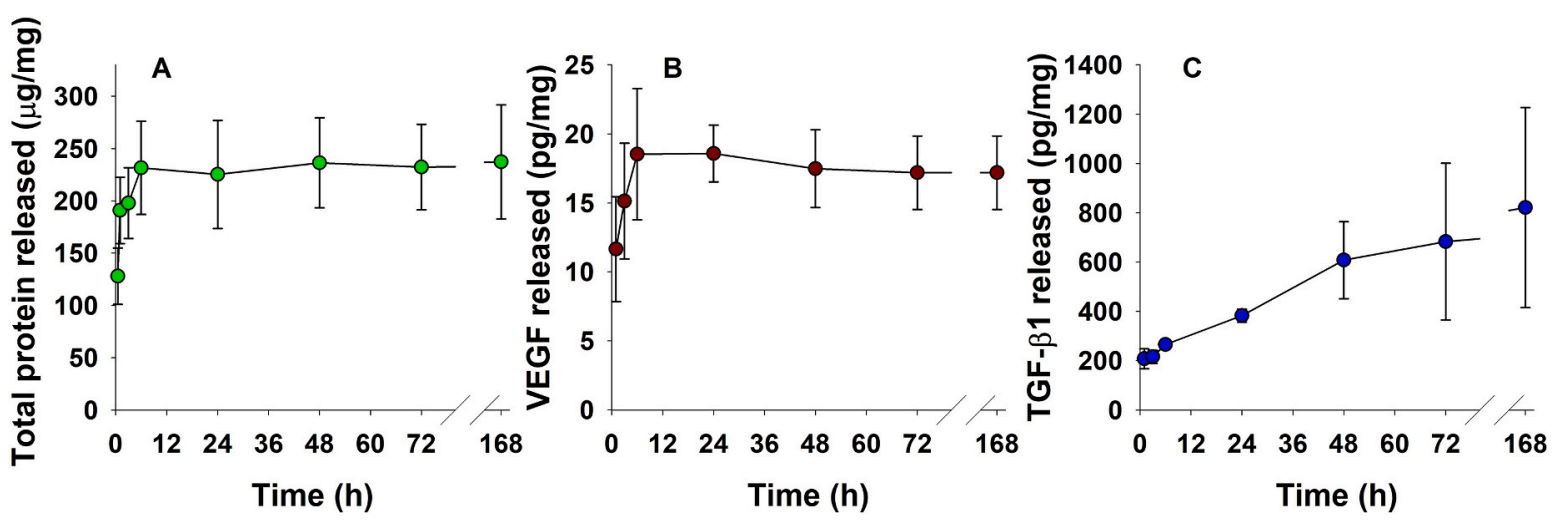

Fig. 5. Cumulative release of (A) total protein, (B) VEGF, and (C) TGF- $\beta 1$ from CMC-PRP scaffolds in $\mathrm{NaCl} 0.9 \%$ at $37^{\circ} \mathrm{C}$. 
process (Liarte, Bernabé-García, \& Nicolás, 2020). Slower release of TGF- $\beta 1$ than of VEGF has also been reported for other PRP-containing scaffolds (Diaz-Gomez et al., 2014) and may be related to structural differences. VEGF has a molecular weight of 27,042 Da and pI 9.21, while TGF- $\beta 1$ molecular weight is $44,341 \mathrm{Da}$ and the $\mathrm{pI}$ is 8.83 (PhosphoSitePlus ${ }^{\circledR}$ v6.5.9.3, 2021). Therefore, both growth factors are positively charged at physiological $\mathrm{pH}$ and can interact with CMC scaffold, but the larger size of TGF- $\beta 1$ may restrict the diffusion rate.

\subsection{In ovo angiogenesis test}

The high vascularity of the chorioallantoic membrane (CAM), which is the extraembryonic membrane of the developing chick embryos, has been extensively exploited to evaluate the angiogenic potential of a wide variety of materials (Azzarello, Ihnat, Kropp, Warnke, \& Lin, 2007; Merckx et al., 2020). A high number of vascular vessels developed radially from CMC-PRP $(96 \pm 15)$ scaffolds as well as from activated PRP deposited directly on the CAM (positive control, $103 \pm 11$ ) (Fig. 6). CMC scaffolds also promoted a significant vascularization $(55 \pm 23)$. The integration of CMC and CMC-PRP scaffolds in the CAM was remarkable after 5 days of incubation, with numerous blood vessels penetrating throughout their macroporous structure. Angiogenesis is a main pillar of wound healing (Veith, Henderson, Spencer, Sligar, \& Baker, 2019), and PDGF and VEGF contained in PRP may synergistically facilitate neovascularization when released from dressings (Diaz-Gomez et al., 2014; Kano et al., 2005; Nour, Imani, Chaudhry, \& Sharifi, 2021).

\subsection{Cell proliferation and migration}

A scratch assay was carried out with MSCs seeded in the migration chambers ( $\mu$-dishes) and incubated in complete medium (negative control) or in release medium from CMC or CMC-PRP scaffolds (24 h release at $37^{\circ} \mathrm{C}$ ). Wound closure percentage was calculated from the initial gap length after 6 and $24 \mathrm{~h}$ (Fig. 7). CMC and CMC-PRP release media reduced the gap significantly faster than the negative control. At $24 \mathrm{~h}$, wound closure was almost complete in CMC and CMC-PRP treated cells, which confirmed that both CMC and PRP enhanced by themselves cell migration. This finding agrees with previous in vivo tests (rabbit cornea) showing that CMC induces cell migration (Garrett et al., 2007).
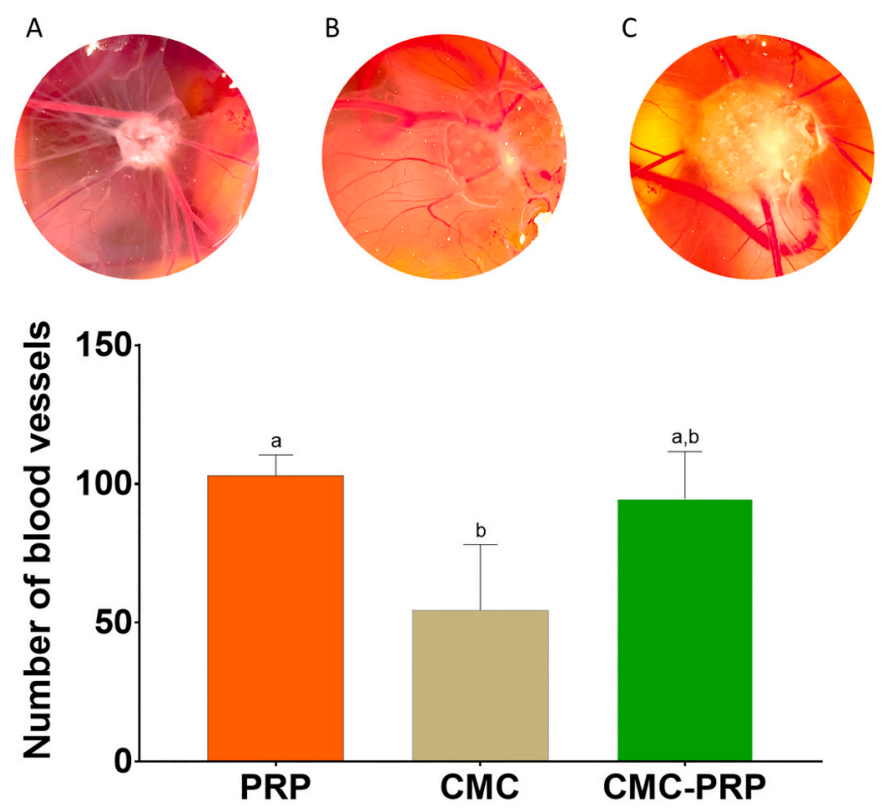

Fig. 6. Formation of blood vessels radially growing in the CAM where (A) PRP, (B) CMC or (C) CMC-PRP scaffolds were deposited and incubated for 5 days. Different letters denote significant differences $(p<0.05 ; n=5)$.
Differently, only CMC-PRP scaffolds significantly increased MSCs proliferation at 48 and $96 \mathrm{~h}(p<0.05)$. The ability of PRP to promote MSCs and fibroblast migration and proliferation has been effectively used to promote tissue regeneration (Devereaux et al., 2020; Qian et al., 2020).

\subsection{In vivo wound healing}

Wound healing performance of the CMC and CMC-PRP scaffolds was evaluated in vivo in a full-thickness wound diabetic rat model that mimics the effect of the imbalanced concentrations of glucose and insulin on recurrent ulcers (Ansell et al., 2018; Qian et al., 2020). Fullthickness skin wounds $(8 \mathrm{~mm})$ were generated on the back of diabetic rats, and the CMC or CMC-PRP scaffold was applied only once, at time 0 , without replacement. Untreated wounds were used as control and the wound closure rate was monitored on days 3, 7, 10 and 14 (Fig. 8 A,B).

Daily inspections of the wounds (facilitated by the transparency of the scaffolds in the first days and gel erosion along time; Fig. 8B) confirmed no signs of inflammation or infection in any group during the 14-day treatment period. CMC-PRP scaffolds significantly reduced the size of the wounds after 3 and 7 days of treatment, compared to untreated wounds (Fig. 8A; $p<0.05$ ). After 3 days, wounds treated with CMC and CMC-PRP scaffolds showed a wound closure rate of $44.1 \pm$ $9.7 \%$ and $50.2 \pm 12.2 \%$, respectively, while the closure rate in the control group was $35.8 \pm 13.1 \%(n=7 ; p<0.02)$. On day 7 , CMC and CMC-PRP treated wounds were less than $50 \%$ of the initial size (closure rates $58.0 \pm 12.3 \%$ and $62.8 \pm 14.7 \%$, respectively) ( $n=7 ; p<0.006$; statistically different with respect to control). On day 10 , the closures rates were approx. $75 \%$. By the end of the study, CMC-PRP treated wounds presented the highest closure $(88.6 \pm 4.7 \%)$.

The effect of the wound dressings on the re-epithelialization of the tissue was evaluated using hematoxylin and eosin staining, which revealed the presence of granulation tissue in the wound bed in all groups on day 3 of wound treatment (Fig. 9 and S4). In the control group the dermis was not completely repaired on day 14, while epidermis appeared as completely repaired at day 14 (falsely closed). CMC-PRP scaffolds promoted the formation of an epithelial layer already at day 3 after wound infliction and the regenerated dermis was significantly thicker than in the control group. Wounds treated with CMC scaffolds developed a continuous epidermal layer that was evident on day 7 and displayed an enhanced dermis formation, although the extension of the dermis layer was not as pronounced as with CMC-PRP scaffolds. Overall, wounds treated with CMC and, in a higher extent, CMC-PRP scaffolds benefited from a faster migration of cells involved in the regeneration. Rapid wound healing have also been found for other PRP-loaded polymeric platforms (Qian et al., 2020; Yassin et al., 2019), but it is evidenced here for first time for CMC solely scaffolds.

Immunohistochemical analysis was also carried out to evaluate the efficiency of tissue regeneration. Vascularization was evaluated by immunofluorescent staining of the newly formed vessels using an antiCD31 antibody, an endothelial cell marker (Fig. S5). On days 7 and 14 , wounds treated with CMC-PRP scaffolds presented the highest amount of blood vessels ( $\mathrm{p}<0.05$; Fig. 9B), which can be attributed to the presence of VEGF in the PRP. Also, porosity and pore interconnectivity may have contribute to angiogenesis and vascular ingrowth of scaffolds (Chiu et al., 2011; Lee, Parthiban, Jin, Knowles, \& Kim, 2021).

The ability of CMC and CMC-PRP scaffolds to promote cell proliferation was examined by analyzing the expression of PCNA, a cell proliferation-specific protein. The highest PCNA-positive cell concentration was found in wounds treated with CMC-PRP scaffolds, suggesting a high proliferation rate in the wound region since the early days of treatment (Fig. S6 and 9C). CMC group also showed a positive effect on the stimulation of cell proliferation compared to control group on days 3 and 7, suggesting that CMC scaffolds promoted a faster proliferation rate in vivo. On day 14, the concentration of PCNA positive cells increased in all groups, but significant differences were still observed between the 
A

$\mathrm{Oh}$

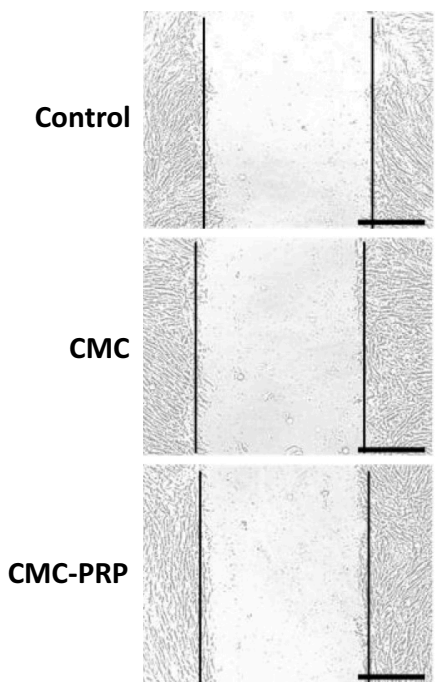

$6 \mathrm{~h}$

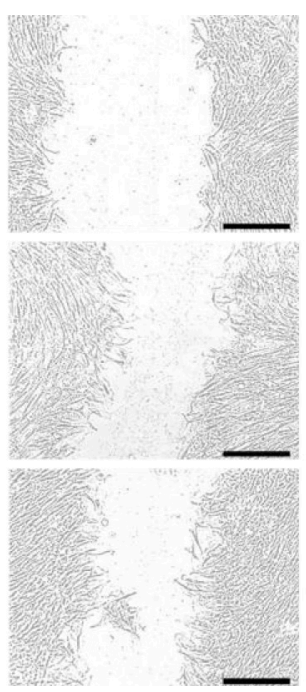

$24 \mathrm{~h}$

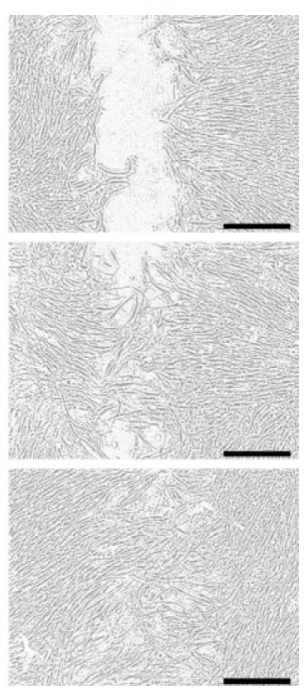

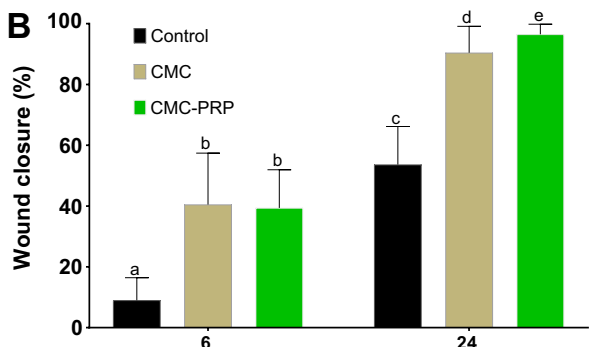

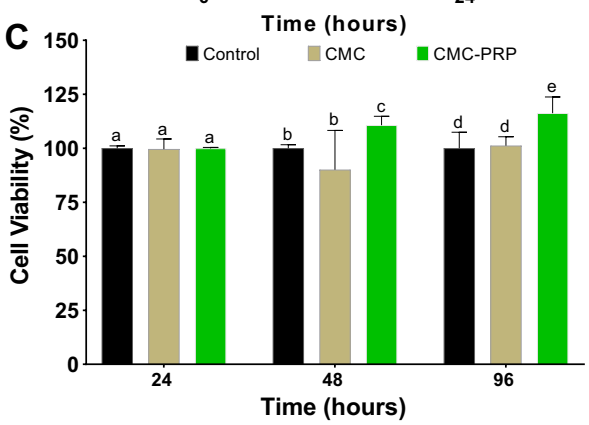

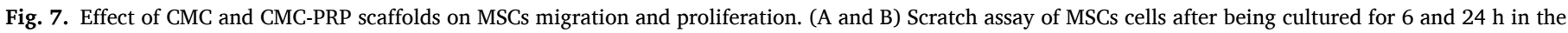

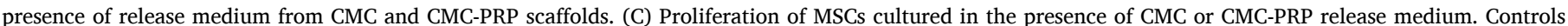

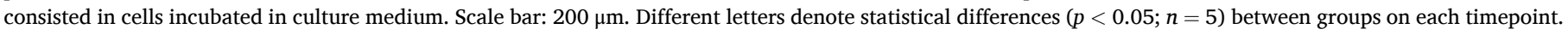
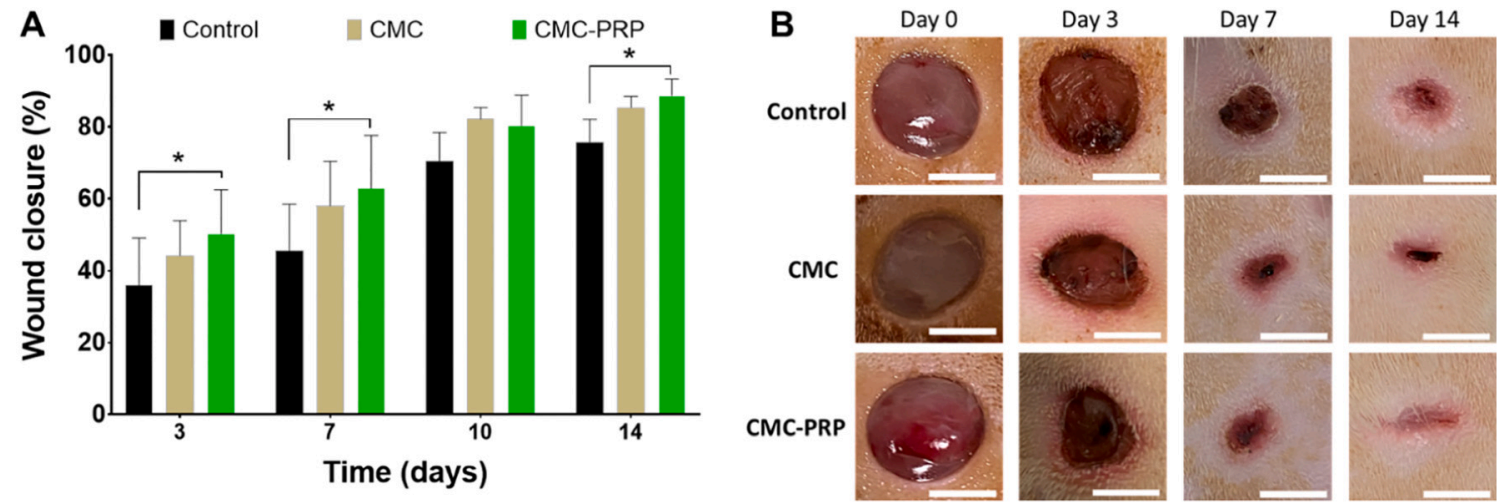

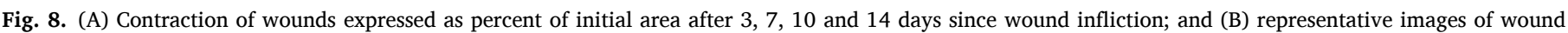

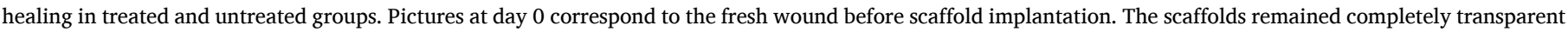
on the wound on day 3. Scale bar: $5 \mathrm{~mm}$. *Significant differences for $\mathrm{p}<0.05(\mathrm{n}=7)$.

CMC-PRP group and the control group, which can be attributed to the generation of an environment rich in growth factors and the upregulation of the expression of growth factors involved in the proliferation of epidermal cells (Tsai et al., 2017; Xu et al., 2020). Nevertheless, synergism between PRP and CMC could not be discarded.

\section{Conclusion}

3D printed porous scaffolds were successfully prepared by extrusion printing using a storable, ready-to-use CMC ink. Dispersions prepared with $15 \%$ w/v CMC and citric acid (20\% with respect to CMC) showed adequate rheological properties for $3 \mathrm{D}$ printing without the need of additional components. Moreover, freeze-drying and heating at $7 \mathrm{~min}$ at $120{ }^{\circ} \mathrm{C}$ rendered scaffolds that exhibited an adequate balance between swelling behavior (exudate uptake) and flexural properties. CMC scaffolds were shown able to induce angiogenesis in ovo and to favor MSCs migration in vitro; these performances being reinforced when the scaffolds were soaked in PRP after printing (CMC-PRP scaffolds). Interestingly, the scaffolds could be loaded with patient-specific PRP immediately before use becoming transparent, which enables a direct monitoring of the healing of the tissue underneath. In the diabetic wound model, a single application of the CMC scaffold promoted efficient dermis and epidermis healing facilitating wound contraction, which confirmed the effect of CMC on cells migration and proliferation even in challenging wounds. The capability of CMC scaffolds to regulate the release of growth factors from PRP can be seen as an additional advantage for accelerating the tissue regeneration. The regulatory status of CMC as component of drug products and medical devices may facilitate the translation of these scaffolds to the clinical arena.

\section{CRediT authorship contribution statement}

Luis Diaz-Gomez: Methodology, Validation, Formal analysis, Writing - original draft, Writing - review \& editing. Iago GonzalezPrada: Methodology, Investigation, Writing - review \& editing. Rosendo Millan: Methodology, Investigation, Writing - review \& editing. Andres Da Silva-Candal: Methodology, Investigation, Writing - review \& editing. Ana Bugallo-Casal: Methodology, Investigation, Writing review \& editing. Francisco Campos: Formal analysis, Resources, Supervision, Writing - review \& editing. Angel Concheiro: 
A

$3 \mathrm{~d}$

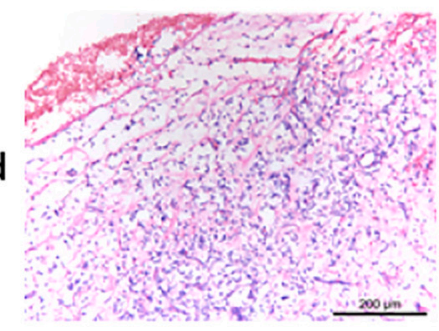

$7 d$

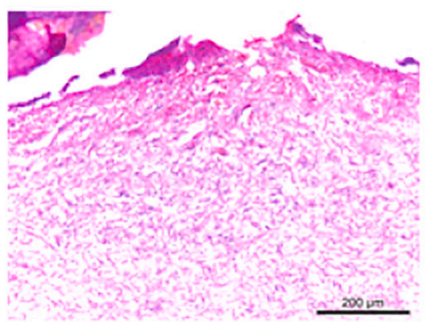

$14 d$

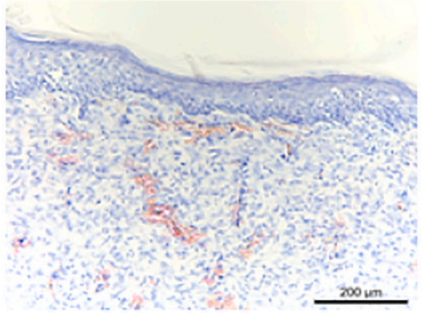

B

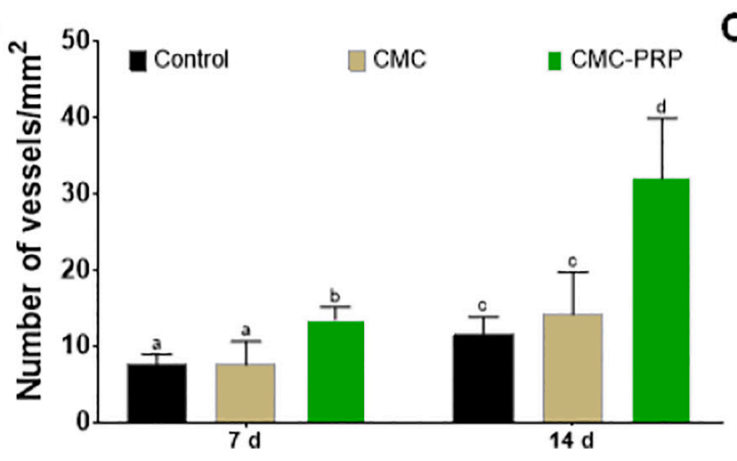

CMC
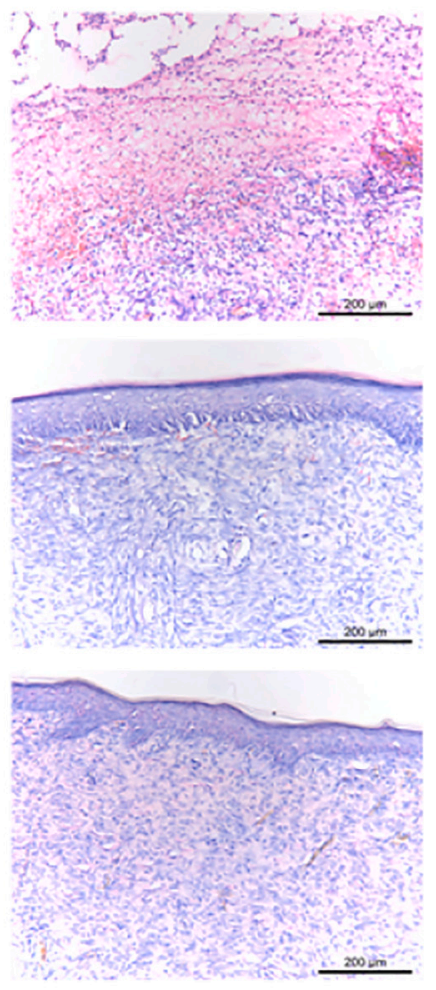

$C^{N}$

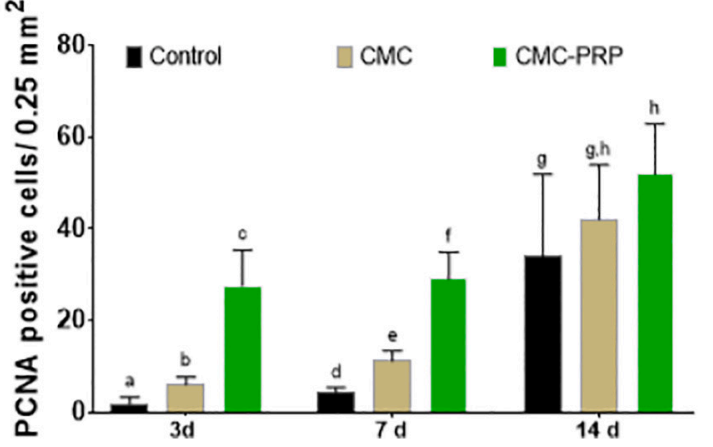

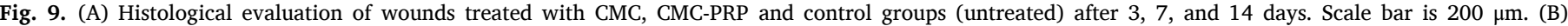

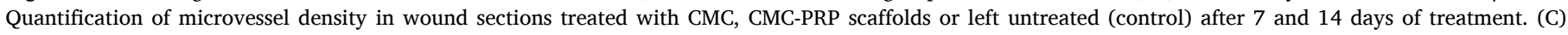

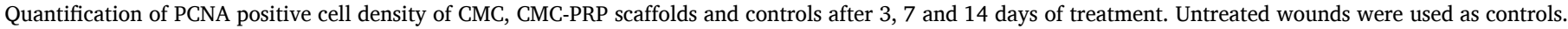
Different letters denote statistical differences $(p<0.05 ; n=7)$ between groups on each timepoint.

Conceptualization, Writing - original draft, Resources, Supervision, Writing - review \& editing. Carmen Alvarez-Lorenzo: Conceptualization, Formal analysis, Writing - original draft, Resources, Supervision, Project administration, Funding acquisition, Writing - review \& editing.

\section{Acknowledgements}

This research was funded by MINECO [SAF2017-83118-R], MCIN [PID2020-113881RB-I00/AEI/10.13039/501100011033] (Spain), Xunta de Galicia [ED431C 2020/17] and European Regional Development Fund (FEDER). L.D-G. acknowledges Xunta de Galicia for a Postdoctoral fellowship [ED481D-2021-014]. A. B-C. thanks a PFIS predoctoral grant [FI18/00071] and A.D.C. thanks a Sara Borrell grant [CD20/00054] funded by Instituto de Salud Carlos III and co-funded by European Union, ESF, "Investing in your future".

\section{Appendix A. Supplementary data}

Supplementary data to this article can be found online at https://doi. $\operatorname{org} / 10.1016 / j . c a r b p o l .2021 .118924$.

\section{References}

Alvarez-Lorenzo, C., Blanco-Fernandez, B., Puga, A. M., \& Concheiro, A. (2013). Crosslinked ionic polysaccharides for stimuli-sensitive drug delivery. Advanced Drug Delivery Reviews, 65(9), 1148-1171.

Ansell, D. M., Marsh, C., Walker, L., Hardman, M. J., \& Holden, K. (2018). Evaluating STZ-induced impaired wound healing in rats. Journal of Investigative Dermatology, 138(4), 994-997.

Arca, H. C., Mosquera-Giraldo, L. I., Bi, V., Xu, D., Taylor, L. S., \& Edgar, K. J. (2018). Pharmaceutical applications of cellulose ethers and cellulose ether esters. Biomacromolecules, 19(7), 2351-2376.

Azzarello, J., Ihnat, M. A., Kropp, B. P., Warnke, L. A., \& Lin, H.-K. (2007). Assessment of angiogenic properties of biomaterials using the chicken embryo chorioallantoic membrane assay. Biomedical Materials, 2(2), 55-61.

Babaei, V., Afradi, H., Gohardani, H. Z., Nasseri, F., Azarafza, M., \& Teimourian, S. (2017). Management of chronic diabetic foot ulcers using platelet-rich plasma. Journal of Wound Care, 26(12), 784-787.

Bao, P., Kodra, A., Tomic-Canic, M., Golinko, M. S., Ehrlich, H. P., \& Brem, H. (2009). The role of vascular endothelial growth factor in wound healing. Journal of Surgical Research, 153(2), 347-358. 
Basu, P., Narendrakumar, U., Arunachalam, R., Devi, S., \& Manjubala, I. (2018). Characterization and evaluation of carboxymethyl cellulose-based films for healing of full-thickness wounds in normal and diabetic rats. ACS Omega, 3(10), $12622-12632$.

Berg, L., Lazaro Martinez, J. L., Serena, T. E., Dhoonmoon, L., \& Ousey, K. (2019). Meeting report: Promoting wound healing by optimising dressing change frequency. Wounds International, 10, 68-75.

Borujeni, S. H., Mirdamadian, S. Z., Varshosaz, J., \& Taheri, A. (2020). Threedimensional (3D) printed tablets using ethyl cellulose and hydroxypropyl cellulose to achieve zero order sustained release profile. Cellulose, 27(3), 1573-1589.

Capanema, N. S. V., Mansur, A. A. P., de Jesus, A. C., Carvalho, S. M., de Oliveira, L. C., \& Mansur, H. S. (2018). Superabsorbent crosslinked carboxymethyl cellulose-PEG hydrogels for potential wound dressing applications. International Journal of Biological Macromolecules, 106, 1218-1234.

Chen, T.-L., Kim, H., Pan, S.-Y., Tseng, P.-C., Lin, Y.-P., \& Chiang, P.-C. (2020). Implementation of green chemistry principles in circular economy system towards sustainable development goals: Challenges and perspectives. Science of the Total Environment, 716, Article 136998.

Chiu, Y.-C., Cheng, M.-H., Engel, H., Kao, S.-W., Larson, J. C., Gupta, S., \& Brey, E. M. (2011). The role of pore size on vascularization and tissue remodeling in PEG hydrogels. Biomaterials, 32(26), 6045-6051.

Coma, V., Sebti, I., Pardon, P., Pichavant, F., \& Deschamps, A. (2003). Film properties from crosslinking of cellulosic derivatives with a polyfunctional carboxylic acid. Carbohydrate Polymers, 51(3), 265-271.

Conceição, J., Farto-Vaamonde, X., Goyanes, A., Adeoye, O., Concheiro, A., CabralMarques, H.Alvarez-Lorenzo, C., ... (2019). Hydroxypropyl- $\beta$-cyclodextrin-based fast dissolving carbamazepine printlets prepared by semisolid extrusion 3D printing. Carbohydrate Polymers, 221, 55-62.

Coviello, T., Alhaique, F., Parisi, C., Matricardi, P., Bocchinfuso, G., \& Grassi, M. (2005) A new polysaccharidic gel matrix for drug delivery: Preparation and mechanical properties. Journal of Controlled Release, 102(3), 643-656.

Dai, L., Cheng, T., Duan, C., Zhao, W., Zhang, W., Zou, X.Ni, Y., ... (2019). 3D printing using plant-derived cellulose and its derivatives: A review. Carbohydrate Polymers, 203, 71-86.

Demitri, C., Del Sole, R., Scalera, F., Sannino, A., Vasapollo, G., Maffezzoli, A.Nicolais, L., (2008). Novel superabsorbent cellulose-based hydrogels crosslinked with citric acid. Journal of Applied Polymer Science, 110(4), 2453-2460.

Devereaux, J., Dargahi, N., Fraser, S., Nurgali, K., Kiatos, D., \& Apostolopoulos, V. (2020). Leucocyte-rich platelet-rich plasma enhances fibroblast and extracellular matrix activity: Implications in wound healing. International Journal of Molecular Sciences, 21(18), 6519.

Diaz-Gomez, L., Alvarez-Lorenzo, C., Concheiro, A., Silva, M., Dominguez, F., Sheikh, F. A.Macossay, J., ... (2014). Biodegradable electrospun nanofibers coated with platelet-rich plasma for cell adhesion and proliferation. Materials Science and Engineering: C, 40, 180-188.

Elliot, S., Wikramanayake, T. C., Jozic, I., \& Tomic-Canic, M. (2018). A modeling conundrum: Murine models for cutaneous wound healing. Journal of Investigative Dermatology, 138(4), 736-740.

Everett, E., \& Mathioudakis, N. (2018). Update on management of diabetic foot ulcers. Annals of the New York Academy of Sciences, 1411(1), 153-165.

Garrett, Q., Simmons, P. A., Xu, S., Vehige, J., Zhao, Z., Ehrmann, K., \& Willcox, M. (2007). Carboxymethylcellulose binds to human corneal epithelial cells and is a modulator of corneal epithelial wound healing. Investigative Opthalmology \& Visual Science, 48(4), 1559.

Ghorpade, V. S., Yadav, A. V., \& Dias, R. J. (2017). Citric acid crosslinked $\beta$ -cyclodextrin/carboxymethylcellulose hydrogel films for controlled delivery of poorly soluble drugs. Carbohydrate Polymers, 164, 339-348.

Gillispie, G., Prim, P., Copus, J., Fisher, J., Mikos, A. G., Yoo, J. J.Lee, S. J., ... (2020). Assessment methodologies for extrusion-based bioink printability. Biofabrication, 12 (2), Article 022003.

Goyanes, A., Allahham, N., Trenfield, S. J., Stoyanov, E., Gaisford, S., \& Basit, A. W. (2019). Direct powder extrusion 3D printing: Fabrication of drug products using a novel single-step process. International Journal of Pharmaceutics, 567, Article 118471.

Habib, A., Sathish, V., Mallik, S., \& Khoda, B. (2018). 3D printability of alginatecarboxymethyl cellulose hydrogel. Materials, 11(3), 454.

Hiltunen, S., Xu, C., Willför, S., \& Backfolk, K. (2018). Thermally induced degradation of NaCMC in water and effects of NaHCO3 on acid formation and charge. Food Hydrocolloids, 74, 32-36.

Hurler, J., Engesland, A., Poorahmary Kermany, B., \& Škalko-Basnet, N. (2012). Improved texture analysis for hydrogel characterization: Gel cohesiveness, adhesiveness, and hardness. Journal of Applied Polymer Science, 125(1), 180-188.

Kanikireddy, V., Varaprasad, K., Jayaramudu, T., Karthikeyan, C., \& Sadiku, R. (2020) Carboxymethyl cellulose-based materials for infection control and wound healing: A review. International Journal of Biological Macromolecules, 164, 963-975.

Kano, M. R., Morishita, Y., Iwata, C., Iwasaka, S., Watabe, T., Ouchi, Y.Miyazawa, K., (2005). VEGF-A and FGF-2 synergistically promote neoangiogenesis through enhancement of endogenous PDGF-B-PDGFR $\beta$ signaling. Journal of Cell Science, 118 (16), 3759-3768.

Kavitha, K. V. (2014). Choice of wound care in diabetic foot ulcer: A practical approach. World Journal of Diabetes, 5(4), 546.

Langkilde, F. W., \& Svantesson, A. (1995). Identification of celluloses with fouriertransform (FT) mid-infrared, FT-raman and near-infrared spectrometry. Journal of Pharmaceutical and Biomedical Analysis, 13(4-5), 409-414.

Lee, J.-H., Parthiban, P., Jin, G.-Z., Knowles, J. C., \& Kim, H.-W. (2021). Materials roles for promoting angiogenesis in tissue regeneration. Progress in Materials Science, 117, Article 100732.
Liarte, S., Bernabé-García, Á., \& Nicolás, F. J. (2020). Role of TGF- $\beta$ in skin chronic wounds: A keratinocyte perspective. Cells, 9(2), 306.

Long, D. W., Johnson, N. R., Jeffries, E. M., Hara, H., \& Wang, Y. (2017). Controlled delivery of platelet-derived proteins enhances porcine wound healing. Journal of Controlled Release, 253, 73-81.

Long, J., Etxeberria, A. E., Nand, A. V., Bunt, C. R., Ray, S., \& Seyfoddin, A. (2019). A 3D printed chitosan-pectin hydrogel wound dressing for lidocaine hydrochloride delivery. Materials Science and Engineering: C, 104, Article 109873.

Lu, B., Wang, T., Li, Z., Dai, F., Lv, L., Tang, F.Lan, G., ... (2016). Healing of skin wounds with a chitosan-gelatin sponge loaded with tannins and platelet-rich plasma. International Journal of Biological Macromolecules, 82, 884-891.

Mallakpour, S., Tukhani, M., \& Hussain, C. M. (2021). Recent advancements in 3D bioprinting technology of carboxymethyl cellulose-based hydrogels: Utilization in tissue engineering. Advances in Colloid and Interface Science, 292, Article 102415.

Melocchi, A., Parietti, F., Maroni, A., Foppoli, A., Gazzaniga, A., \& Zema, L. (2016). Hotmelt extruded filaments based on pharmaceutical grade polymers for 3D printing by fused deposition modeling. International Journal of Pharmaceutics, 509(1-2), 255-263.

Merckx, G., Tay, H., Lo Monaco, M., van Zandvoort, M., De Spiegelaere, W., Lambrichts, I., \& Bronckaers, A. (2020). Chorioallantoic membrane assay as model for angiogenesis in tissue engineering: Focus on stem cells. Tissue Engineering Part B: Reviews, 26(6), 519-539.

Nour, S., Imani, R., Chaudhry, G. R., \& Sharifi, A. M. (2021). Skin wound healing assisted by angiogenic targeted tissue engineering: A comprehensive review of bioengineered approaches. Journal of Biomedical Materials Research Part A, 109(4), 453-478.

Oliverius, M., Drozd, J., Bratka, P., Whitley, A., Mohlenikova Duchonova, B., \& Gürlich, R. (2021). A new silver dressing, StopBac, used in the prevention of surgical site infections. International Wound Journal, 1-7. iwj.13593.

Paribok, I. V., Solomyanskii, A. E., \& Zhavnerko, G. K. (2016). Patterns of the adsorption of bovine serum albumin on carboxymethyl dextran and carboxymethyl cellulose films. Russian Journal of Physical Chemistry A, 90(2), 466-469.

Pavlovic, V., Ciric, M., Jovanovic, V., Trandafilovic, M., \& Stojanovic, P. (2021). Plateletrich fibrin: Basics of biological actions and protocol modifications. Open Medicine, 16 (1), 446-454.

Paxton, N., Smolan, W., Böck, T., Melchels, F., Groll, J., \& Jungst, T. (2017). Proposal to assess printability of bioinks for extrusion-based bioprinting and evaluation of rheological properties governing bioprintability. Biofabrication, 9, Article 044107.

Pettignano, A., Charlot, A., \& Fleury, E. (2019). Carboxyl-functionalized derivatives of carboxymethyl cellulose: Towards advanced biomedical applications. Polymer Reviews, 59(3), 510-560.

PhosphoSitePlus ${ }^{\circledR}$ v6.5.9.3. (2021). www.phosphosite.org accessed July.

Pino-Sedeño, T., Trujillo-Martín, M. M., Andia, I., Aragón-Sánchez, J., Herrera-Ramos, E., Iruzubieta Barragán, F. J., \& Serrano-Aguilar, P. (2019). Platelet-rich plasma for the treatment of diabetic foot ulcers: A meta-analysis. Wound Repair and Regeneration, 27, 170-182.

Polamaplly, P., Cheng, Y., Shi, X., Manikandan, K., Zhang, X., Kremer, G. E., \& Qin, H. (2019). 3D printing and characterization of hydroxypropyl methylcellulose and methylcellulose for biodegradable support structures. Polymer, 173, 119-126.

Qian, Z., Wang, H., Bai, Y., Wang, Y., Tao, L., Wei, Y.Liu, H., ... (2020). Improving chronic diabetic wound healing through an injectable and self-healing hydrogel with platelet-rich plasma release. ACS Applied Materials \& Interfaces, 12(50), 55659-55674.

Ramli, N. A., \& Wong, T. W. (2011). Sodium carboxymethylcellulose scaffolds and their physicochemical effects on partial thickness wound healing. International Journal of Pharmaceutics, 403(1-2), 73-82.

Rodríguez, R., Alvarez-Lorenzo, C., \& Concheiro, A. (2003). Cationic cellulose hydrogels: Kinetics of the cross-linking process and characterization as $\mathrm{pH}$-/ion-sensitive drug delivery systems. Journal of Controlled Release, 86(2-3), 253-265.

Rodriguez-Tenreiro, C., Alvarez-Lorenzo, C., Rodriguez-Perez, A., Concheiro, A., \& Torres-Labandeira, J. J. (2006). New cyclodextrin hydrogels cross-linked with diglycidylethers with a high drug loading and controlled release ability. Pharmaceutical Research, 23(1), 121-130.

Saghazadeh, S., Rinoldi, C., Schot, M., Kashaf, S. S., Sharifi, F., Jalilian, E. Khademhosseini, A., ... (2018). Drug delivery systems and materials for wound healing applications. Advanced Drug Delivery Reviews, 127, 138-166.

Savage, A. (1971). Ethers. In N. Bikales, \& L. Segal (Eds.), Vol. 5. Cellulose and cellulose derivatives (pp. 785-809). New York: Wiley-Interscience.

Seoane-Viaño, I., Januskaite, P., Alvarez-Lorenzo, C., Basit, A. W., \& Goyanes, A. (2021), Semi-solid extrusion 3D printing in drug delivery and biomedicine: Personalised solutions for healthcare challenges. Journal of Controlled Release, 332, 367-389.

Singh, T., Kothapalli, C., Varma, D., Nicoll, S. B., \& Vazquez, M. (2014). Carboxymethylcellulose hydrogels support central nervous system-derived tumorcell chemotactic migration: Comparison with conventional extracellular matrix macromolecules. Journal of Biomaterials Applications, 29(3), 433-441.

Suresh, D., Suryanarayan, S., Sarvajnamurthy, S., \& Puvvadi, S. (2014). Treatment of a non-healing diabetic foot ulcer with platelet-rich plasma. Journal of Cutaneous and Aesthetic Surgery, 7(4), 229.

Tsai, W.-C., Yu, T.-Y., Lin, L.-P., Lin, M.-S., Wu, Y.-C., Liao, C.-H., \& Pang, J.-H. S. (2017). Platelet rich plasma release promotes proliferation of skeletal muscle cells in association with upregulation of PCNA, cyclins and cyclin dependent kinases. Platelets, 28(5), 491-497.

Veith, A. P., Henderson, K., Spencer, A., Sligar, A. D., \& Baker, A. B. (2019). Therapeutic strategies for enhancing angiogenesis in wound healing. Advanced Drug Delivery Reviews, 146, 97-125.

Vo, A. Q., Zhang, J., Nyavanandi, D., Bandari, S., \& Repka, M. A. (2020). Hot melt extrusion paired fused deposition modeling 3D printing to develop hydroxypropyl 
cellulose based floating tablets of cinnarizine. Carbohydrate Polymers, 246, Article 116519.

Wang, S., Xiong, Y., Chen, J., Ghanem, A., Wang, Y., Yang, J., \& Sun, B. (2019). Three dimensional printing bilayer membrane scaffold promotes wound healing. Frontiers in Bioengineering and Biotechnology, 7, 348.

Xu, P., Wu, Y., Zhou, L., Yang, Z., Zhang, X., Hu, X.Cheng, B., ... (2020). Platelet-rich plasma accelerates skin wound healing by promoting re-epithelialization. Burns \& Trauma, 8, Article tkaa028.

Yang, H. S., Shin, J., Bhang, S. H., Shin, J.-Y., Park, J., Im, G.-I.Kim, B.-S., ... (2011) Enhanced skin wound healing by a sustained release of growth factors contained in platelet-rich plasma. Experimental and Molecular Medicine, 43(11), 622.
Yassin, G. E., Dawoud, M. H. S., Wasfi, R., Maher, A., \& Fayez, A. M. (2019). Comparative lyophilized platelet-rich plasma wafer and powder for wound-healing enhancement: Formulation, in vitro and in vivo studies. Drug Development and Industrial Pharmacy, 45(8), 1379-1387.

Zennifer, A., Senthilvelan, P., Sethuraman, S., \& Sundaramurthi, D. (2021). Key advances of carboxymethyl cellulose in tissue engineering and 3D bioprinting applications. Carbohydrate Polymers, 256, Article 117561.

Zidan, A., Alayoubi, A., Asfari, S., Coburn, J., Ghammraoui, B., Aqueel, S.Ashraf, M., (2019). Development of mechanistic models to identify critical formulation and process variables of pastes for 3D printing of modified release tablets. International Journal of Pharmaceutics, 555, 109-123. 